\title{
Methodology of Implementing Virtual Reality in Education for Industry 4.0
}

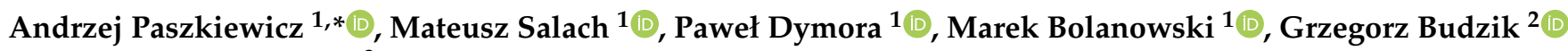 \\ and Przemysław Kubiak ${ }^{3}$
}

check for updates

Citation: Paszkiewicz, A.; Salach, M.; Dymora, P.; Bolanowski, M.; Budzik,

G.; Kubiak, P. Methodology of Implementing Virtual Reality in Education for Industry 4.0. Sustainability 2021, 13, 5049. https:// doi.org/10.3390/su13095049

Academic Editor: Barbara Motyl

Received: 27 March 2021

Accepted: 28 April 2021

Published: 30 April 2021

Publisher's Note: MDPI stays neutral with regard to jurisdictional claims in published maps and institutional affiliations.

Copyright: (c) 2021 by the authors. Licensee MDPI, Basel, Switzerland. This article is an open access article distributed under the terms and conditions of the Creative Commons Attribution (CC BY) license (https:// creativecommons.org/licenses/by/ $4.0 /)$.
1 Department of Complex Systems, The Faculty of Electrical and Computer Engineering, Rzeszow University of Technology, 35-959 Rzeszów, Poland; m.salach@prz.edu.pl (M.S.); Pawel.Dymora@prz.edu.pl (P.D.); marekb@prz.edu.pl (M.B.)

2 Department of Machine Design, Faculty of Mechanical Engineering and Aeronautics, Rzeszow University of Technology, 35-959 Rzeszów, Poland; gbudzik@prz.edu.pl

3 Faculty of Electrical and Computer Engineering, Rzeszow University of Technology, 35-959 Rzeszów, Poland; 152148@stud.prz.edu.pl

* Correspondence: andrzejp@prz.edu.pl

\begin{abstract}
This paper presents an entirely new approach to the use of virtual reality (VR) in the educational process for the needs of Industry 4.0. It is based on the proposed comprehensive methodology, including the design, creation, implementation and evaluation of individual courses implemented in a VR environment. An essential feature of the new methodology is its universality and comprehensiveness. Thanks to that, it can be applied in such areas as higher education, aviation, automotive, shipbuilding, energy and many others. The paper also identifies the significant advantages and disadvantages of VR-based education that may determine its use scope and profile. In addition, on the basis of the proposed methodology, a model of a training station using VR technology has been developed to enable the realization of training classes in the field of firefighting activities that should be undertaken during the hazard arising from the operation of a numerically controlled production machine. Results of the conducted training using this station were also presented. The study showed the potential of training based on a virtual environment to improve participants' skills and knowledge. The development and implementation of adequate courses in the VR environment can reduce costs and increase the safety and efficiency of employees' performed activities.
\end{abstract}

Keywords: virtual reality (VR); immersive learning; education training methodology; Industry 4.0

\section{Introduction}

Recent decades are characterized by the rapid development of many areas of life. This development is associated with changes of social, cultural and economic nature. Many of them are a direct effect of technological development, especially development in the area of information systems. An excellent example of such changes is the fourth industrial revolution, called Industry 4.0 [1,2], which leads to automation and computerization of all processes associated with production and distribution [3-7]. It is important to remember that the field of influence of any revolution can be very wide. Even though the changes in question concern primarily the processes of design, manufacturing and logistics, they have an impact on the culture of work, social relations and, above all, they are associated with the need to provide an appropriately qualified staff of specialists in various fields. It is the dynamically changing labor market that increasingly shapes educational programs. Only economies that are able to quickly adapt methods and means of teaching and learning new content come out victorious in confrontation with the needs of today's global labor market. Considering the current and future needs of the market and society, it is necessary to search for, develop and enhance new methodologies, frameworks and tools and techniques used in the education process. One of the relatively new and still not much-used solutions is virtual reality (VR) technology [8-10]. 
By providing the user with a variety of visual, auditory and even tactile stimuli, VR has great potential for increasing cognitive processes' effectiveness and attractiveness. These processes can be considered in narrow or broad terms. In the first case, they refer to higher brain functions that allow processing information in the nervous system and involve receiving, storing, transforming and inputting information into the environment. In the second case, they refer to features of post-cognitive processes for creating/constructing and modifying knowledge about the environment. Considering the high immersion level of VR systems, it can be concluded that this technology, in a general sense, provides cognitive processes in both aspects. VR technology users can experience conditions comparable or even identical to the real world but also find themselves in an entirely imaginary space. Currently, diverse solutions are being developed that, to varying degrees, can "transfer" and "immerse" the user into the world of VR. Thanks to its features, VR is gaining popularity every year in various areas of life, i.e., in entertainment, in industry and in education, science and research. One of the most important of these areas is Industry 4.0. Specifically, in this case, VR technology can be dedicated to carrying out training processes and testing and verifying entire processes, individual devices and industrial technologies [11-13]. Due to the enormous potential benefits that the widespread use of VR in the industry can bring, many companies and educational and scientific institutions are conducting research and development work to develop completely new solutions, as well as to obtain additional functionalities in the field of VR technology.

It is also important to highlight a very important aspect of the use of VR technology, which has been exemplified recently by the prevailing epidemic of the SARS-CoV-2 virus. Restrictions on mobility, the large percentage of people in quarantine and recommendations related to maintaining social distance and avoiding face-to-face meetings have resulted in the rapid evolution of the existing educational process focused on remote learning. This situation revealed significant drawbacks and limitations of contemporary forms and tools used in the remote education process. These limitations were significantly related to practical training areas, access to advanced equipment, apparatus and whole stands and technological lines. Analyzing this situation, it can be concluded that one of the potential solutions to meet the needs of providing alternative forms of practical education is the development and dissemination of solutions based on VR [14,15].

Unexpected events like a pandemic and the simultaneous development of technology can help trigger a new VR-based education revolution. An important factor that strengthens the rationale for the widespread adoption of this form of education is the ability to provide comparable or identical experiences to those of the real-world environment. Moreover, such an experience is usually underpinned by positive emotions that enhance the didactic process's effectiveness and can be reflected in obtaining better learning outcomes. Additionally, it should be noted that the use of VR technology is consistent with classic and proven models and assumptions of the didactic process, such as experiential learning or situational learning. The indicated foundations of learning theories emphasize the key role that experience plays in these processes and, above all, are compatible with the natural way of learning and development, especially for adults [16].

It has been shown that the use of VR technology in hands-on learning related to strictly engineering subjects can enhance students' level of integration, interaction and reduce the time spent learning specific material [17]. It can also provide students with repetitive exercises that increase the efficiency and effectiveness of learning without increasing costs due to the use of additional consumables and availability of devices while providing a safe learning environment. Therefore, the VR environment is an essential part of the modern educational process in knowledge acquisition, skills and verification in vocational and technical education. Moreover, it allows transforming practical experience into valuable knowledge and skills, which is especially important and appreciated in the industry.

Considering the potential of using VR technology in the educational process, it is necessary to develop a methodology for implementing this technology in education, with particular emphasis on the requirements and needs of Industry 4.0. The new methodology 
has a universal character and is dedicated both to the academic environment, as well as to the training environment dedicated to the employees of enterprises. Taking into account the needs of Industry 4.0 in terms of training future engineers in the area of new technologies, the training objectives for both groups are similar. The obtained results confirm that the proposed methodology can systematize, schedule and execute the design and development work for projects based on VR technology for the needs of Industry 4.0 and at the same time provides a degree of confidence for those involved in the management, coordination and execution of the various phases and stages of implementation, as well as the entire project.

The rest of the paper is organized as follows: Section 2 is a reference to works on VR technology evolution and the actual state of the art. Section 3 refers to the methodological approach to using the VR environment in education and evaluation to develop future Industry 4.0 engineering staff's professional skills. Section 4 presents in detail the proposed by the author's original methodology, which formulates the main phases of the dedicated industry training courses implemented in the VR environment. This section also defines the main stakeholder groups who are actively involved in the whole process and included in the methodology. These assumptions formed the foundation for research work on the validation of capabilities and the proposed methodology's effectiveness at the example of the real-life application. The implementation details in Unity 3d environment, sample training scenario and obtained research results are presented in Section 5. The work ends with a summary of the obtained research results, conclusions and further research statement.

\section{Previous Research}

The history of solutions similar to VR dates back to the 19th century. It was at that time that the concept of the stereoscope appeared. Sir Charles Wheatstone's research showed that the human brain could combine two images (one for each eye) so that the image seems to have a sense of depth and space. This concept was utilized by Wheatstone in 1838 in the construction of the first stereoscope using two mirrors set at a $45^{\circ}$ angle that reflected images set opposite each other, creating a spatial image [18]. For further breakthroughs, it was necessary to wait over a century. In 1957, Morton Heilig created the "Sensorama", which he later patented in 1962 [19]. One might be tempted to say that it was a form of analog VR. The solution he presented provided additional stimuli such as stereo sounds, seat tilt, vibration, smell and wind gusts. Thanks to that, it achieved a relatively high level of immersion at that time. The next step in VR development was patenting a device called "Telesphere Mask" in 1960 [20]. It was the first Head-Mounted Display model, similar in design to today's VR goggles. However, at that time, miniaturized projection lamps were used to transmit stereoscopic television images. This provided a wide $140^{\circ}$ viewing angle and stereo sound.

In 1965, Ivan Sutherhand in his essay "The Ultimate Display" [21], presented a concept concerning a virtual world, i.e., "The Ultimate Display," as a room in which the computer can control any subject inside. Three years later, in 1968, Sutherhand [22] created the first head-mounted VR device called "The Sword of Damocles." He combined a stereoscopic display with a computer program that displayed simple virtual shapes that could change their perspective when the user moved their head. With computer and television technology development, it was not until 1975 that the first interactive VR environment was presented. It was the result of work conducted for several years by Myron Krueger. The solution was based on the use of dark rooms with large projection screens that surrounded the user. People in separate rooms could interact with the image of another user [23]. There was also an option to change colors and interact with virtual objects. In 1977, a system called "Aspen Movie Map" was developed at MIT. It enabled a virtual tour around the city, realized similarly to the now popular application Google Street View. The program was created based on pictures taken from a car driving through the city. It was not an HMD system, but it used an interaction system and made the impression that the displayed (virtual) reality could transport people to other places. The 1980s brought other significant 
developments leading to modern VR systems. One of them was the development of a glove with optical sensors to measure finger flexion [24].

Meanwhile, in the second half of the 1980s, the "Visually Coupled Airborne Systems Simulator" (VCASS) was developed [25]. The system offered piloted a virtual view in which real-time information was displayed. The first widely available entertainment system based on VR technology appeared in the early 1990s. It included a set of arcade games. Almost simultaneously, an immersive VR environment in a room was developed, called "Cave Automatic Virtual Environment" (CAVE) [26]. This system was based on displaying high-resolution images on the walls of a room. The first HMD systems appeared on the market with the launch of Nintendo's "Virtual Boy" console. However, this solution only provided images in shades of red. In terms of modern widespread VR systems, the turning point was Google Street View 2D's implementation in 2007 based on immersive media technology. A 3D version soon followed and in 2014, the same company released "Cardboard," cardboard self-assembling goggles designed to be a housing for popular smartphones. Its popularity led to the actual development of wearable solutions and VR technology itself. As a result, over the past few years, companies have been influential in commercializing VR technology. For this purpose, it has launched various models and types of VR goggles. Most of these solutions allow receiving in a relatively highresolution image as well as surround sound. In addition, some of these systems have been supplemented with handheld controllers and motion tracking systems that allow the user to interact with the computer.

Nowadays, there are many areas of VR technology applications and more are being added every year. It can be assumed that this technology has the potential to be used in all areas of human activity. One of them, which has grown the fastest recently, was widely understood entertainment. This is due to the fact that the same frameworks are used to create modern games, as well as to build a virtual environment dedicated to VR. Therefore, entertainment in VR is top-rated and the solutions designed for this market are becoming better and more attractive for the recipient. However, a significant factor that limits the complete dissemination of this form of entertainment (at a level similar to traditional consoles) is the costs associated with the purchase of both high-quality goggles and a powerful computer that would meet the requirements of graphics generation within VR. Other areas where VR technology is gaining importance include education, medicine, design, military and mechanical engineering. An exciting project in the field of education is the "Virtual Reality Education eXpansion" (VREX) system [27].

It is a cloud-based platform that is mainly used in China and is designed to enhance the knowledge of sciences such as biology, astronomy, mathematics, medicine, engineering, etc. The surgery training course available on this platform is also an excellent example in this regard. A similar application area is available through the "Anatomy Builder VR" program developed by researchers at Texas A\&M University [28]. It allows students to learn about the anatomy of an animal's limbs and execute pre-designed scenarios. Another example is a system developed at the University of North Carolina at Chapel Hill, which, thanks to the three-dimensional presentation of human organs, allows doctors to precisely plan the distribution of radiation beams used in cancer treatment [29]. Additionally, thanks to the huge amount of data collected today and with the use of 3D visualization, VR technology can be used for organ exploration by doctors and students [30]. A huge potential of this technology is in the field of rehabilitation. Therefore, VR can create appropriate simulated environments in which assessment and treatment of cognitive, emotional and motor problems can occur. One of the main advantages of using VR in education is exploring normally inaccessible objects, learning about complex processes and understanding difficult to observe phenomena and check and test procedures that are dangerous to perform in real-world settings. An example of such solutions is a virtual tour of the "Virtual Energy Center" at Louisiana State University (LA, USA), in particular of "The Solar Technology Applied Research and Testing (START) Laboratory," to which access is restricted [31]. Another example could be the use of VR to demonstrate molecular 
mechanisms in chemical engineering courses, e.g., by visualizing chemical molecules [32]. In the field of chemistry teaching, a tool has also been developed at Hanyang University to support student education in this domain. It provides students with access to a virtual laboratory where they perform procedures under teachers' supervision and support. Operating in a virtual world eliminates the potential danger of burning the body with dangerous chemicals and damaging the laboratory station. This example confirms the fact that, in many cases, VR technology allows increasing awareness and skills in areas that by their nature are dangerous and threaten health and life. In such cases, classical education is often ineffective. Therefore, based on the Occupational Health and Safety Administration (OHSA) information, researchers Alyssa M. Peña and Eric D. Ragan from Texas A\&M University developed a VR simulator that presents safety rules for construction sites [33]. The developed scenarios referred to real events related to a construction disaster. However, the aspect of construction and especially architecture can have a completely different, more pleasant face. Thanks to VR, both designers and architects and ordinary users can feel the space of future projects and inaccessible or very distant buildings. An excellent example of this is the possibility to walk through non-existent or destroyed houses, such as the Frauenkirche in Dresden [34]. Another example is the "CubeVR" system developed by researchers at Colorado State University and Florida International University, allowing students in architecture classes to build objects using pre-given materials [35]. Additionally, by applying textures to the elements, the student has a more realistic idea of working with the material. Another discipline where VR is also beneficial is scientific visualization. An impressive example of such an application is the virtual wind tunnel developed at NASA Ames Research Center. Using this program, scientists can use a data glove to input and manipulate streams of virtual smoke, airflow around a digital model of an aircraft or space shuttle [34]. The use of VR is not limited only to education or entertainment. A huge potential of this technology has in the area of widely understood industry. Especially in the case of challenges related to the implementation of the Industry 4.0 concept and in the future with Industry 5.0 in the technological, social and educational area, as these challenges require the search for adequate methods and means. Modern industrial processes in many sectors of the economy are very complex. Therefore, the use of VR for modeling and testing individual elements of production lines and individual stages or entire manufacturing processes has great potential and can contribute to increased efficiency and reliability of already real solutions. Implementing processes in a virtual environment can help identify various problems and thus, reduce the time and costs associated with their elimination in already implemented industrial processes. Of course, there are many examples of VR applications in areas such, as automotive, aerospace, oil, energy, etc. [36-38]. One of the solution it uses is virtual visualization of airflow dynamics in the area of aircraft structural analysis [39]. In the aviation industry, the use of VR can be used to train mechanics and ground crew more accurately and quickly, without the cost and danger associated with practicing on real aircraft. In this case, the technology provides a safe environment for testing procedures and methods to diagnose and repair aircraft components. The paper [40] presents many examples of VR applications in the aviation industry, such as VR training systems for the Boeing 737. The mechanics practice thrust reversal using procedures in the aircraft manual. There are also solutions used by commercial air carriers and general aviation training organizations. In 2012, Aerosim and LATAM Airlines developed the "Aerosim Virtual Maintenance Trainer" platform for training aircraft technicians to locate selected Airbus A320 and A330 aircraft components to test troubleshooting procedures for these components [41]. Fascinating assumptions about modeling industrial processes using VR simulators were presented in work [42]. It defines basic functions, including interactions between workers and various automation systems, such as robots and indicates the need to consider a wide set of realized tasks. Solutions based on so-called digital twins are also available. For example, the paper [43] presents a method for programming robots using VR and digital twins. In this solution, a VR system is used to record human movements in a virtual environment, which are then reproduced by a real robot. 
As one can see, by using VR, engineers can accelerate the design and testing of their products. VR technology is also becoming part of industrial practice, which is being used not only to educate workers but also to create workplaces that are compatible with the new Operator 4.0 paradigm such as augmented operator, virtual operator [44]. Research interviews conducted with Industry 4.0 representatives showed that they see great potential in these solutions but perceive a big problem in their implementation in the production environment. The lack of a well-defined framework or methodology for planning the implementation process, estimating its costs and duration, holds back the decision to implement VR technology in the education and training processes inherent in modern industrial systems. Thus, a key issue in the context of wider application of VR in the field of industry-oriented education is the development of an appropriate methodology for the implementation of VR courses into the enterprise practice in order to increase the efficiency of the educational process and organize the stages of course preparation according to the requirements of the enterprise. The works partially addressing issues in this area are mainly conducted in academic centers. The paper [45] presents a simplified teaching methodology for VR practical courses in engineering education. This work presents methods and means for creating VR courses but omits the stage associated with adapting the created course to the environment's requirements to be simulated. Using VR in the educational cycle, which includes creating architectural objects, is presented in the paper [46]. The described simplified methodology is dedicated to one type of solution, i.e., the design of architecture in urban planning.

An interesting review of current solutions used in the field of immersive VR can be found in the paper [47]. The authors of this article also cite research showing that about $96 \%$ of universities already use VR in the UK. The discussed article focuses on using VR in the educational process and identifies students from engineering-related faculties as the primary audience for these solutions. For this group of people, who will soon enter the job market, it will be natural to use VR as a learning and development environment. VR educational projects implemented in academia are often created as a result of research work or experiments. To apply these experiences in the industry, they need to be structured into clear steps for designing and implementing a course. In paper [48], a straightforward three-step training course implementation model is proposed, but it does not specify the exact steps to be taken during the implementation of a VR course and does not provide an example of applying the proposed methodology. The paper [49] proposes an interesting methodology for creating courses based on virtual learning factory (VLF). The proposed solution is dedicated to students and mainly limited to courses devoted to reconfigurable manufacturing. An interesting approach to structuring the learning process using VR is presented in the article [50]. The presented methodology concerns the transformation from the traditional teaching factory to teaching factory 4.0 using, among other things, the idea of VR. The course creation process itself is omitted in this methodology. The paper [51] presents a methodological approach to the use of VR in education and the evaluation of designers' creativity. Similarly, the paper [52] presents a methodological approach to developing professional skills using a VR environment. The paper presents an interesting model SMART hybrid lab development model, which can be treated in methodology. It distinguishes five essential stages which allow to implementation of VR in the teaching process. This solution is addressed to the academic environment and can be successfully used to complement students' education process. VR reality is also indicated as one of the methods suitable for transferring knowledge to new generations of engineers entering the job market. In the article [53], the authors emphasize that VR and AR are appropriate educational techniques for the iMillennials generation that take advantage of this group of engineers' characteristics for their rapid acquisition of new skills and adaptation to changing technological needs. The paper [54] highlights the role of learning stations where students can complete their projects including the final project. This paper proposes using Industry 4.0-oriented flexible manufacturing system (FMS) as an educational tool. The analysis of this solution clearly shows that it can also be offered 
as a VR environment. Such an approach would increase the focus on practical training so important from the point of view of the iMillennials generation and would expand access to modern teaching positions simulated with VR and AR. The use of these techniques allows for a more flexible approach to education and rapid adaptation of the educational process to the labor market's needs, which is particularly important from the point of view of educating engineers for Industry 4.0 [55]. The analysis of previous work in the field of VR shows the great potential of this technology. The spectrum of specialists available at universities and the nature of their activities allow for relatively quick creation of VR courses (with students' participation) and incorporate them into the educational process. As mentioned earlier, the higher education community has already noticed the need to standardize the process of creating VR courses, which translates into proposals for new methodologies and frameworks to streamline the creation of VR courses. The proposed approaches only work in university settings. It is assumed that a student taking a VR course knows the area of VR techniques and domain knowledge gained in earlier stages of education. The use of these methodologies directly in industrial practice, i.e., in enterprises, training companies and industrial centers, is impossible or very difficult. Therefore, the authors of this article decided to develop a new methodology for developing courses in the industrial environment to increase the educational process's efficiency, which will be a coherent and homogeneous approach to implementing VR technology in the education and training of engineers using VR environment. The solution proposed in the article can also be seen in terms of a reference model consisting of six stages. It allows dividing the work related to the course's development and implementation between specialized entities or project groups that deal with the work in specific stages. This would positively improve the quality of the course and reduce the development time.

\section{An Analysis of the Pros and Cons of VR in Terms of the Educational Process}

Considering the importance of the educational process and its consequences on later professional, social and even family relationships, it is crucial to analyze the advantages and disadvantages of VR, especially in relation to teaching processes. Therefore, the authors in Table 1 have gathered in their opinion the most important ones. At first, it should be noted that VR is characterized by a very high level of user involvement in the user's activities. This feature is essential in acquiring knowledge and practical skills, which are sought and desired by various industry areas. In many cases, it replicates real-life situations very well while providing interactions similar to those known from the real world. Due to the high level of immersion, the user experience increases the effectiveness of the educational process. This form of education can better remember and understand the knowledge presented with its help and gain experience in the implementation of complex activities, procedures and experiences. A considerable advantage of VR technology is the ability to repeatedly test complex training scenarios corresponding to processes and procedures, including those of a critical nature. Thanks to the repetition of activities with a reduction of additional costs, you can effectively improve employees' skills. What's more, the use of VR in the process of training for the needs of the high-tech industry, including in the context of Industry 4.0, allows to eliminate physical risk for users (e.g., possible injury, burns, etc.), as well as to eliminate the potential threat to the actual hardware or software resulting from misconfiguration and improper implementation of the procedure by trainees during the exercises. A significant advantage is the ability to carry out individual training stages without considerable time and space limitations (e.g., use of remote access technology). It encourages cooperation between different educational and industrial centers. It opens broad prospects for exchanging experience with top-class specialists in particular fields, who usually can be only to a limited extent involved in traditional forms of classes. Taking into account a significant reduction in the consumption of many natural materials, VR technology fits into one of the most critical issues of today's humanity, namely the creation of more ecological workplaces and education, as well as organic waste and decarbonization of selected processes. Another essential advantage of this solution is its scalability, flexibility 
and potential for remote working. This, in turn, realized a wide area of application in the case of situations such as a pandemic, natural disaster, etc., in the context of the SARSCoV-2 virus epidemic, which limited or, in many cases, prevented the implementation of educational processes in a traditional way.

Table 1. Advantages and disadvantages of using VR technology in education.

\begin{tabular}{|c|c|}
\hline Advantages & Disadvantages \\
\hline $\begin{array}{c}\text { It enables creating complex test scenarios, experiments and } \\
\text { experiments that are difficult to implement in a } \\
\text { real-world setting. }\end{array}$ & $\begin{array}{l}\text { Costs are associated with creating an appropriate educational } \\
\text { station using VR technology based on professional hardware } \\
\text { and software. }\end{array}$ \\
\hline $\begin{array}{l}\text { Enables one to gain confidence in implementing technical } \\
\text { procedures and activities. }\end{array}$ & $\begin{array}{l}\text { Requires a lot of work to create a virtual environment with } \\
\text { many test scenarios and details. }\end{array}$ \\
\hline $\begin{array}{l}\text { Allows for multiple repetition of experiences, experiments, } \\
\text { or situations. }\end{array}$ & Limited scope or lack of ready-made teaching scenarios. \\
\hline $\begin{array}{l}\text { Saves money and time associated with setting up actual } \\
\text { test stations. }\end{array}$ & No real consequences for mistakes and errors made. \\
\hline Allows to perform exercises at any place and at any time. & The ability to make users addicted to the virtual world. \\
\hline Ensures scalability of educational activities. & Limits interpersonal contacts and experiences. \\
\hline Reduces consumption of real resources. & High probability of acquiring routine in the actions taken. \\
\hline Ensures safety of operations. & Potential for health problems for users. \\
\hline $\begin{array}{l}\text { Has the ability to adapt and apply to various fields and areas } \\
\text { of education. }\end{array}$ & The possibility of ignoring basic laws of physics. \\
\hline $\begin{array}{l}\text { Increases the ability to communicate and collaborate with } \\
\text { people in remote locations. }\end{array}$ & $\begin{array}{l}\text { It reproduces better or worse the given reality but is not able to } \\
\text { replace it entirely. }\end{array}$ \\
\hline
\end{tabular}

Of course, despite the numerous advantages, some limitations and difficulties associated with the use of VR technology in educational processes should be noted. These include the need to provide a dedicated working environment, which is associated with investment costs and provide highly qualified specialists to develop ready virtual environments. However, it is essential to remember that high costs are characteristic of newly implemented solutions. As VR technologies become more widely used, their availability and diversity will increase and costs will decrease. It should also be remembered that the VR world cannot fully imitate the real world, especially in terms of the number of details and all the laws of physics (at least for now, for example, lifting a fire extinguisher does not consider its weight, variation of ambient temperature). This property is also associated with the possibility of acquiring a kind of routine by the trainees, the effects of which in this environment are minor, but in reality, can lead to errors, damage and negligence, significantly affecting the functioning of the real system, its efficiency and ability to continue to operate. Therefore, it is crucial at the stage of project assumptions to clearly indicate the most important skills necessary to be acquired in the course and the elements and phenomena that should be mapped in the most detailed way in the VR scenarios. Additionally, research is being conducted on the effects of VR on human health. The results of this research should also provide recommendations and recommendations for upgrading the technology itself, the tools available and the mode of delivery of courses and training.

\section{Proposed Methodology}

Teaching methodology originates from the field of finding effective ways of teaching specific subjects by analyzing the objectives, content, methods and organizational forms of education. It comes down to discovering ways (means) of rational action through the most thorough analysis of educational content and experience-based recognition of methods and standards used in the field. The methodology must take into account the conditions and 
individuality of the area in which it is applied. There are many methodologies dedicated to specific fields of education [56-58]. However, the dynamically changing reality in the area of challenges accompanying industrial revolutions forces the necessity of searching and implementing new solutions adjusted to current needs.

Therefore, a methodology was developed to create courses/training dedicated to the needs of the industry. Its fundamental elements are presented in Figure 1.

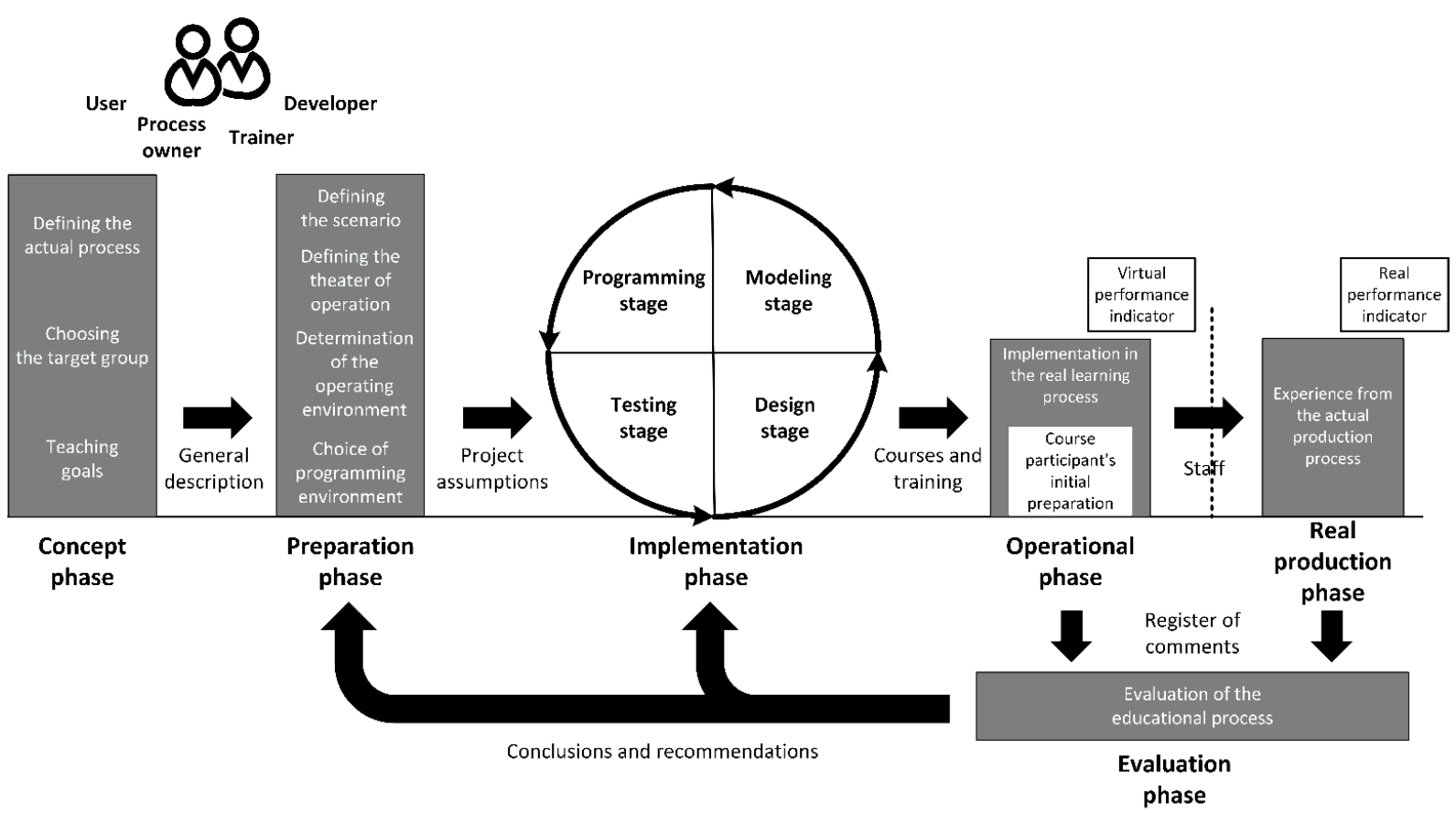

Figure 1. Methodology for developing VR training dedicated to industry needs.

The methodology is divided into six phases. Within each phase, there are specific activities and outputs. Each phase is a separate part of the process aimed at developing a valuable course that meets real needs.

The concept phase begins the process of creating the target solution. Although the choice of final IT tools and VR devices is not usually made at this point, it plays a very important role. It is during this phase that the actual process to be transferred to the virtual environment is defined. This process must be described in terms of general assumptions, expectations, requirements and perceptions of the target course participant. Therefore, it is not necessary to clearly define the target audience that will use it. Their level of experience with VR technology, age and previous work experience will determine the definition of assumptions about the training scenario and how it will be implemented in VR. This will also help to define the most important learning objectives properly. These goals should be realistic and achievable by the trainees with the use of VR technology and at the same time enable the acquisition of relevant knowledge and expected skills. As a result of the work carried out in the concept phase, a document such as a general description of training should be created, containing a general outline of the training process.

The preparation phase includes detailing the information necessary to implement the target solution. In this phase, it is required to precisely define the training scenario, including individual actions performed by the participant, their effects and the system's reaction to the mistakes made. In this phase, based on the description of the actual process, the elements that make up the theater of operations are defined. Those that are necessary from the training process's point of view are determined and those that can be omitted. As part of this work, a description is made of the detail of all the objects that make up the virtual action environment. No less important is the determination of the operating environment, i.e., acceptable VR devices from the business point of view (cost, availability). 
All the above elements will allow choosing the environment (framework, graphics engine) on the basis of which the target training will be created. The final effect of the preparation phase will be the project assumptions.

The implementation phase includes four stages that make up the activities related to the actual production of training in VR technology. The first stage is the design stage. In this stage, the project team defines the virtual environment's precise parameters, all objects, actions and events according to the previously described training scenario. At this stage, the final decision is made which objects and even which of their elements/subassemblies will be in the next step accurately modeled and which only visualized using textures. To make this possible, it is necessary to precisely define the VR environment's functions, operating conditions, requirements for interaction between the various elements of the VR environment, the required level of reliability, security and control of the training scenario. As a result of this work, it is possible to obtain several technical proposal variants, which are analyzed in terms of detailed technical and economic parameters at a further stage of design. The final result of this stage is a technical design, including complete implementation documentation. The next stage within the implementation phase concerns the modeling stage, modeling the environment, including objects in it, preparing textures, etc. This work produces, among other things, accurate object meshes. At this point, the project team uses the documentation of the real environment prepared in the concept phase. In justified cases, this stage can be partially paralleled with the programming stage, i.e., implementing all the training scenario assumptions in the selected framework. The virtual world is "brought to life at the programming stage," and the appropriate immersion level is ensured. This results in a technologically and functionally coherent VR environment based on modern solutions necessary for implementing the training process. An integral part of the implementation phase is the testing stage. In this stage, it is necessary to carry out tests related to the functionality, efficiency of the developed solution, as well as the perceived level of impression and, above all, effectiveness of achieving the assumed teaching objectives. The tests should consider different groups of users, i.e., from people advanced in functioning in the VR environment to people as close as possible to the target group. Future training coaches should be involved in the work at this stage. As a result of the implementation phase's work, a dedicated VR environment is created to enable specific training to be conducted and implementation and operational/user documentation.

The operational phase is related to providing proper training within the target groups. This phase should be implemented with the active participation of trainers with appropriate qualifications and experience both on the level of the actual process and the VR environment's operation. Contrary to what one might think, this stage does not end the didactic process. As a result of adequately conducted training, we get a pre-prepared staff. However, taking into account the responsibility associated with the activities performed in a real production environment, it is necessary to conduct tests in production conditions. Thanks to such attempts, it is possible to obtain the final data on the effectiveness of the VR environment's training. Well-conducted VR training will reduce these tests to a minimum saving time, money and, most of all, increasing the level of competence, which will result in increased work efficiency.

The methodology does not in any way impose specific performance indicators, including virtual indicators. Due to the diversity of training and learning objectives, these indicators may vary to a large extent. Examples of such indicators could be the time taken by the user to complete particular stages, the number of mistakes made, or simply completing the entire course. The operational phase includes an essential element, i.e., the course participant's initial preparation to work in the VR environment. Because many people may be participating in this form of training for the first time and taking into account the changing tools and theatrical activities (individual for each course), this part of the VR environment's training implementation can significantly determine the effectiveness and efficiency of the entire training. 
The real production phase, at first glance, seems that it does not belong to the production process of the VR environment. However, considering that its effectiveness can be seen in the performance of procedures in the real world, we realize the importance of this stage. Failure to link the evaluation of the production processes' effectiveness with the conducted training in the real environment and to confront them adequately makes it impossible to evaluate them reliably and reliably introduce changes, improvements and corrections to the existing scenario and form of training. Therefore, all experiences, including positive and negative, suggestions for changes and any comments should appear in the register of comments, which will become a fundamental source of data for the evaluation phase. At this stage, the procedures' virtual performance indicators should be compared with the real performance indicators. Their comparison can be one of the important elements of evaluating the effectiveness of training in a VR environment. Of course, as in the case of virtual indicators, the methodology does not impose specific actual indicators. However, it assumes that both groups will be equivalent to each other so that it is possible to compare them.

The evaluation phase is necessary for the proper functioning of the didactic processes. It refers to the evaluation of the progress of trainees and the collection of experiences to improve the VR environment in the context of learning processes. For this purpose, a register of comments is created and collected during VR and testing in a real production environment. The source of these comments can be trainees, trainers and other stakeholders. Based on the review of these comments, conclusions and recommendations are made to improve the training, e.g., adapt to new needs.

The methodology also identifies four primary stakeholder groups: users, process owner and contractor.

- Process owner: a person who has adequate knowledge of how the actual process to be transferred to the virtual world works. His or her involvement is required during all phases of VR training development. Knowledge and experience of the process owner influence the quality of the created training.

- Trainer: the role of a trainer is usually independent of the role of the process owner. Of course, the trainer should be aware of the actual process, but his main focus should be on the training's effectiveness and efficiency in a VR environment. The trainer's knowledge and experience in this area should be considered in all phases of training development.

- User: a person or a group of people to whom VR training is dedicated. Their expectations do not always have to be precisely specified in the initial phases of creating training. This usually stems from their previous experience in working with VR technology and knowledge of the actual process. However, as the dedicated training is created, their involvement should increase and their comments should be more and more detailed.

- Developer: representatives of the entity creating the training for the industry. The requirement is for the developer to have extensive experience both in VR solutions and in understanding manufacturing automation processes. For understandable reasons, the developer may be assisted by specialists from various fields in order to ensure the highest quality of the created system.

\section{A Comparison of Methodologies}

Table 2 compares the properties of the proposed methodology with solutions known from the academic literature and the professional press. The number of available solutions that include even a fragmentary definition of the exact steps of course development is very limited. The following areas or parameters were selected for comparison:

- Scenario size describes the ability of the proposed solution to create large and complex scenes taking into account aspects such as the ability to clearly divide work, iterative refinement of stages. 
- The phase/stage approach refers to the division of work into task-separated phases of activity, as well as stages.

- The duration of the project is determined by the possibility of dividing the tasks of developing a course into stages, the possibility of outsourcing the work, clear definition of the objectives of a given stage, etc.

- The application areas specify whether the approach can be used to create courses for industrial or higher education environments.

- The cascade or spiral approach focuses on whether the solution implements mechanisms of evolutionary, spiral development of the project or whether it is based on the classic waterfall approach.

- The reusability of the solutions developed at each stage touches on a very important issue. It determines to what extent the developed solutions can be reused to create new courses. This reduces the cost and time of development.

- The flexibility of using the model is a property describing the spectrum of issues that can be covered by the VR course prepared in the given methodology.

- The required stakeholder interaction determines whether it is possible, or even required, to involve internal and external stakeholders during the creation of the course in particular phases and stages of the design and development process and its implementation.

- Documentation complexity refers to the amount of time it takes to create design documentation that covers all the steps of a given methodology.

- Detailed distinction of technical aspects of the project implementation determines how much emphasis the given methodology puts on the accuracy of defining technical parameters. It is a very important parameter because the precision of the definition of technical aspects affects the ability to determine the cost and time of a task, which in turn is the basis for making business decisions in the area of course implementation.

Table 2. A comparison of the proposed methodology with other solutions.

\begin{tabular}{|c|c|c|c|c|}
\hline Feature & $\begin{array}{l}\text { The Proposed } \\
\text { Methodology }\end{array}$ & VLF [49] & $\begin{array}{c}\text { Lernig Factory } \\
{[[50,59]}\end{array}$ & $\begin{array}{c}\text { SMART Hybrid Lab } \\
\text { Development Model [52] }\end{array}$ \\
\hline Scenario size & Small, medium, large & Small & Small, medium & Small, medium \\
\hline The phase/stage approach & Yes & Partially & $\begin{array}{c}\text { Creating VR is one } \\
\text { of the steps }\end{array}$ & Partially \\
\hline The duration of the project & $\begin{array}{l}\text { Short, possibility to } \\
\text { outsource tasks } \\
\text { in stages }\end{array}$ & $\begin{array}{l}\text { Long, no clear links } \\
\text { between stages }\end{array}$ & Medium to long & Long \\
\hline The application areas & $\begin{array}{c}\text { Industry, } \\
\text { higher education }\end{array}$ & Higher education & Higher education & $\begin{array}{c}\text { Industry, } \\
\text { higher education }\end{array}$ \\
\hline $\begin{array}{l}\text { The cascade or } \\
\text { spiral approach }\end{array}$ & Spiral & Cascade & Cascade & Cascade \\
\hline $\begin{array}{c}\text { The reusability of the } \\
\text { solutions developed at } \\
\text { each stage }\end{array}$ & Very large & Small & Small & Partial \\
\hline $\begin{array}{l}\text { The flexibility of using } \\
\text { the model }\end{array}$ & Wide & $\begin{array}{l}\text { Production lines } \\
\text { only }\end{array}$ & $\begin{array}{l}\text { Specific product } \\
\text { lines and issues }\end{array}$ & Wide \\
\hline $\begin{array}{c}\text { The required } \\
\text { stakeholder interaction }\end{array}$ & Yes & Yes & Yes & Yes \\
\hline Documentation complexity & Medium & Low/medium & Low/medium & Difficult to determine \\
\hline $\begin{array}{l}\text { Detailed distinction of } \\
\text { technical aspects of the } \\
\text { project implementation }\end{array}$ & Very high level of detail & Low level of detail & No & Low level of detail \\
\hline
\end{tabular}


On the basis of the summary presented in Table 2, it can be concluded that the proposed methodology is characterized primarily by high implementation potential in different application areas. It is flexible and allows estimation of the cost of course implementation and estimating the time of course development. Moreover, in the proposed methodology, more time should be spent on the preparation of documentation. Preparing precise documentation for each stage allows to reuse the developed elements and accelerates the process of developing new courses, e.g., by using code reuse techniques.

\section{A Real Life Example of the Methodology's Application}

The necessity of developing adequate to the needs of Industry 4.0 methodology of developing VR pieces of training resulted from the expectations of representatives of the industries of aerospace, automotive, armaments, etc. The scope of courses and training implemented by companies from these sectors of the economy is very different and concerns both general procedures used in industrial plants and specialized works connected with specific technologies and manufacturing processes. However, taking into account the confidentiality of most of these types of solutions for demonstration purposes, a project of a training station model was developed using VR technology. It enables the implementation of training classes in the field of fire actions to be taken during the threat arising from the operation of a numerically controlled production machine. Such training corresponds to real processes/procedures commonly used in industry. Therefore, it can be used in almost any modern factory and in training for students and young technicians. Thanks to this, it covers a wide group of potential customers. An important feature of this particular training is to reduce the danger associated with real fire situations. Therefore, training on fire procedures in most cases is only theoretical. Using VR technology, one can conduct this type of training in conditions similar to the real world.

The training's main didactic goal is to develop repeatability and high efficiency of safety activities related to fire extinguishing of a manufacturing station based on a computerized numerical control (CNC) machine. As part of the conceptual phase, a general description presenting the training process outline was created. This description included the following content:

"The course assumes virtual training of the user in the execution of procedures for extinguishing an existing fire in a given object, such as a machine workstation in the factory. The training should prepare the user for the correct leveling of existing dangerous situations, including the machine's emergency shutdown, correct activation of fire protection systems, and dedicated materials to extinguish the fire. The user should have several fire extinguishers with different compositions and adapted to extinguishing equipment under dedicated voltage at his disposal. The user must be familiar with the machine's parameters to extinguish the machine with the appropriate type of extinguisher at the final stage. During the lesson, the user should be able to return to an earlier point in the lesson to check or hear a command again. The application should collect data related to the execution time of the fire hazard leveling process and examine the user's effectiveness during the extinguishing stage of the machine."

The entire training scenario was divided into four major stages, grouping related events in the trainee's virtual environment and actions (Figure 2).

Stage I isolates the event of a CNC machine failure. During this event, the user is required to observe the machine's behavior and take appropriate action at the proper time. After a specific time, the $\mathrm{CNC}$ machine will start to fire. When the malfunction occurs, the user's task is to shut down the machine using a dedicated button. The action taken by the user in this regard is mapped graphically and audibly so that the user can be sure of the correctness of his action. In stage II, the user must activate a manual call point. This action and its sequence in the whole procedure results directly from safety rules. For this purpose, the user must locate the ROP located on the room's wall and then break the protective glass as quickly as possible and press the button. Stage III is the most time-consuming 
and the most complicated. It involves selecting the appropriate extinguisher and directly extinguishing the machine. The user's task is to locate the appropriate extinguisher, reach it and pull it from the box. The training covers the availability of three types of extinguishers: foam extinguishers, snow extinguishers and powder extinguishers.

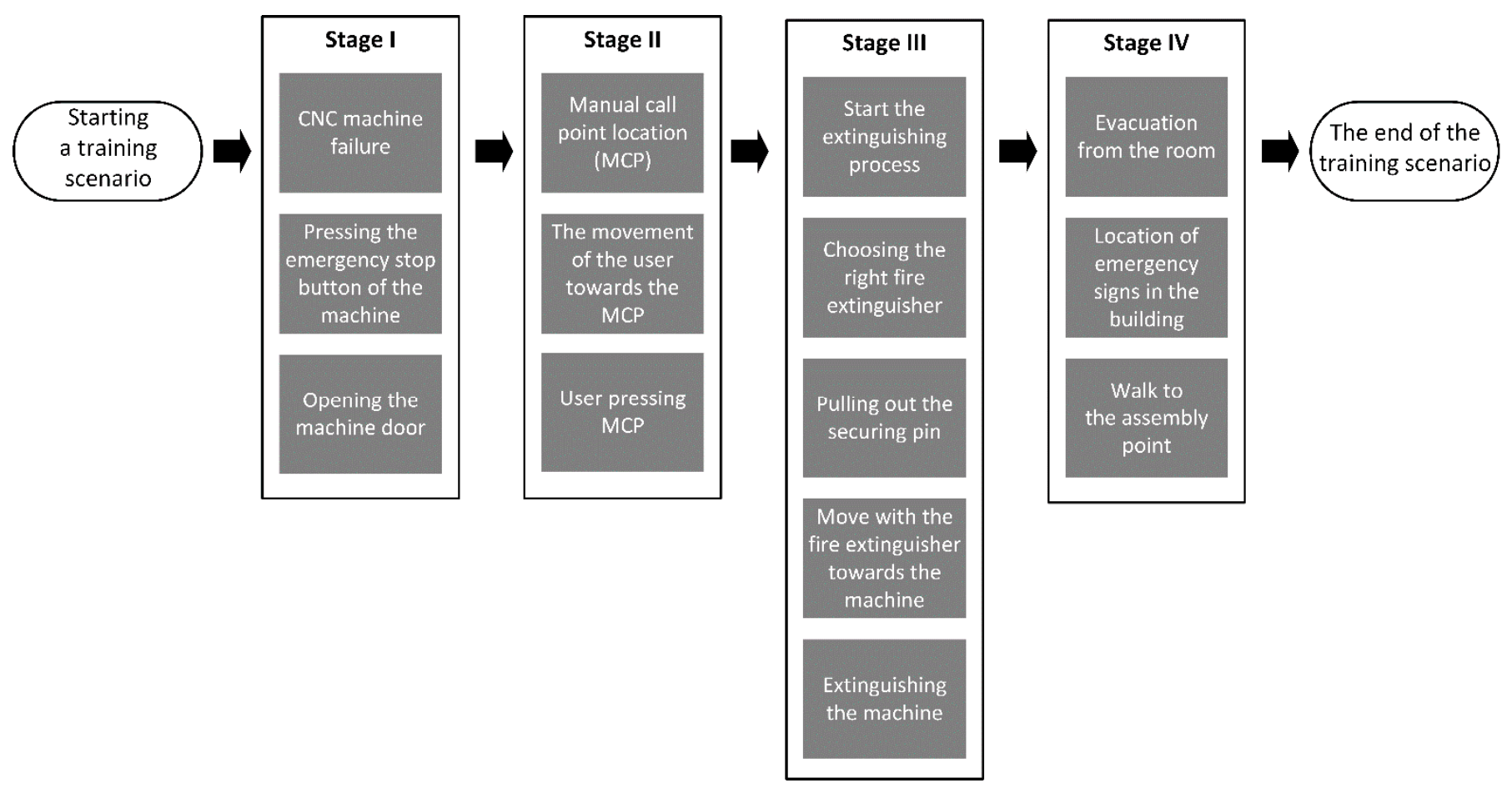

Figure 2. Diagram of a sample training scenario.

Only one of these three meets the appropriate standards and can be used to extinguish production machinery. According to the guidelines, the correct choice is a snow extinguisher. These extinguishers can be found in many rooms as they are dedicated to extinguishing all kinds of electronics, precision machinery and electrical equipment, usually up to 1000 volts. It is a red cylinder of different capacities equipped with liquid gas carbon dioxide and is available in various types. Other fire extinguishers are not designed for electrical machinery.

In some cases, their use can cause damage to the machinery as well as exposing yourself to danger, especially in the case of fire extinguishers that are not suitable for equipment with a given voltage. The speed with which the extinguishers are located, their proper selection and reaching the fire extinguisher directly impacts the extinguishing process's success. In the next step, the user must unlock the extinguisher, reach the machine with it and start the extinguishing process using the grasp and trigger buttons. Of course, it is also necessary to correctly direct the so-called "snow" jet. In the last stage of the training scenario, after extinguishing the fire, the user must leave the room as quickly as possible and follow the evacuation signs to the evacuation assembly area.

The preparation phase defined all the basic elements of a theater of action in a VR environment:

- production building with equipment;

- $\quad$ selected CNC machine mapped;

- $\quad$ elements of personal protection of the user required on the production site;

- $\quad$ system of 3 fire extinguishers;

- manual fire warning device;

- fire alarm system;

- elements of evacuation signs; 
- $\quad$ simulation of fire and extinguishing of CNC machine;

- evacuation site;

- $\quad$ user message system.

Additionally, a system of errors, warnings and appropriate messages directed to the user was included. This system took into account, among others, the wrong sequence of actions taken by the user, wrong choice of fire extinguisher and lack of elements of personal protection of the user, e.g., helmet, goggles.

To create a VR environment, the Unity graphic engine was used. Thanks to the integration of this environment with Microsoft Visual Studio software, it was possible to write individual parts of the target application's code. Another important component used in the project is dedicated VR glasses. Oculus Rift glasses version CV1 was used due to their availability by the developers when working on the project. The Unity environment is well integrated with the Oculus glasses through developed components and classes and objects available to developers. The selected glasses have two OLED-type displays with a resolution of $1080 \times 1200$ per eye and a refresh rate of $90 \mathrm{~Hz}$ and a viewing angle of 110 degrees. The distance between the screens can be set using a sliding button installed on the device's bottom. The total viewing resolution is $2160 \times 1200$ pixels. The device has built-in 3D audio headphones to which one can easily transfer audio from applications. The main positioning system of the VR glasses is a system called a constellation. This system consists of two modules in which IR LEDs are implemented to communicate with sensors embedded in the VR glasses that allow mapping the glasses' position in six points of freedom - three-axis rotation tracking and three-axis position tracking. A set of dedicated Oculus Touch controllers was selected for control and manipulation in the VR environment. All the above information formed the basis for the development of the design assumptions.

The implementation phase was carried out in accordance with the methodology developed and adopted for this project. As a result of this work, an environment was created, the elements of which can be seen in Figure 3.

During the operational phase, 20 students between the ages of 22 and 25 who had no previous experience with fire hazards were trained and were without knowledge of VR in entertainment, such as video games presentations during company festivals. The group of selected students included representatives from the faculty of Computer Science and Automation and Robotics. They also represented engineering and Master's degree studies. Such recruitment was aimed at reflecting the diversified community of engineers who enter the job market. It was also a consequence of discussions and consultations with representatives of high technology industries, including companies from the aerospace, automotive and additive manufacturing sectors. Considering the needs of Industry 4.0 in terms of employee training and present-day education at technical universities, it can be concluded that both areas are similar. Table 3 presents selected aspects of similarity between both target environments (groups).

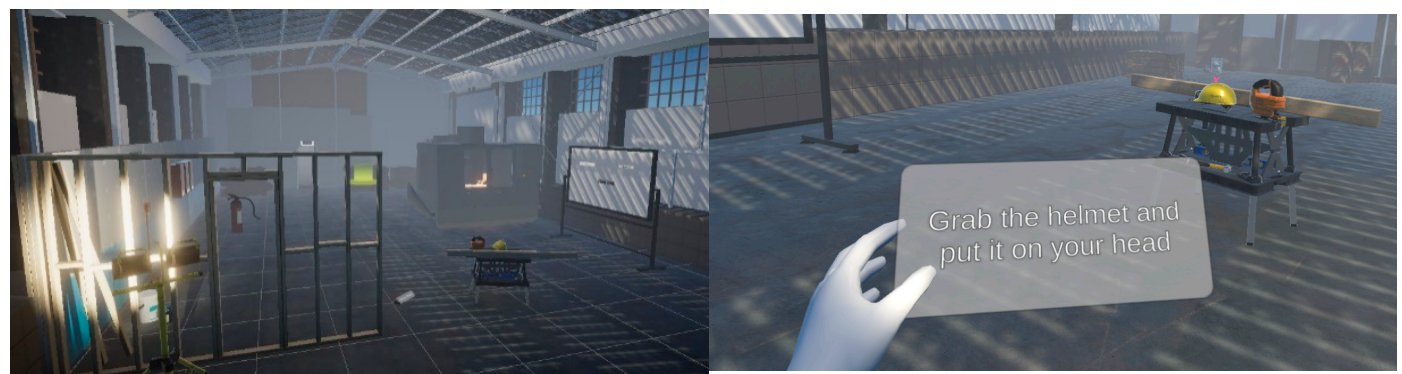

(a)

(b)

Figure 3. Cont. 


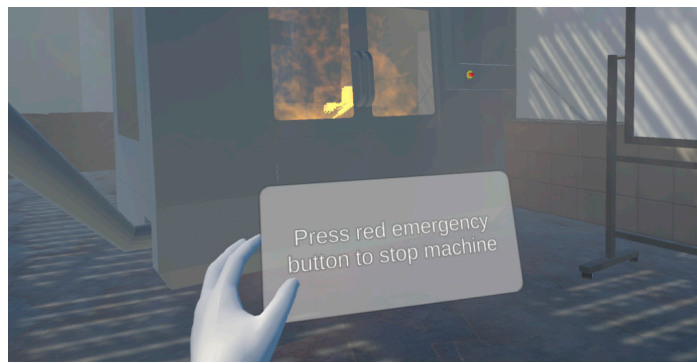

(c)

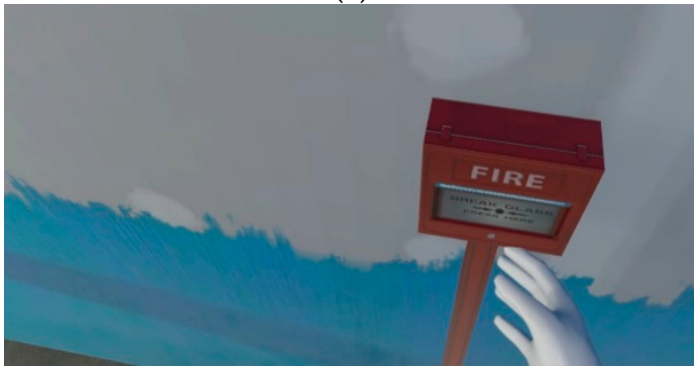

(e)

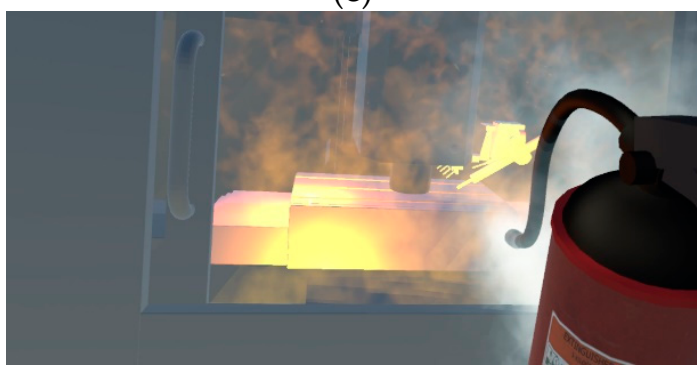

(g)

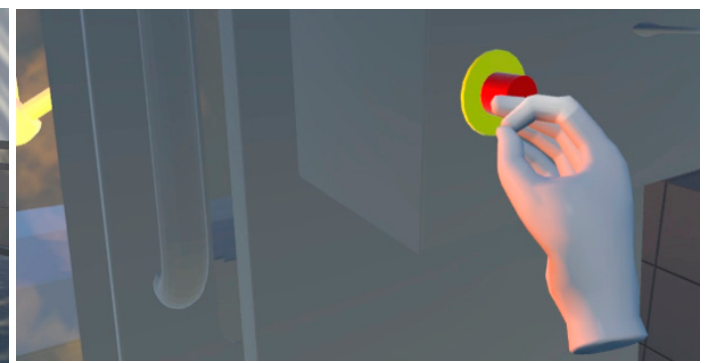

(d)

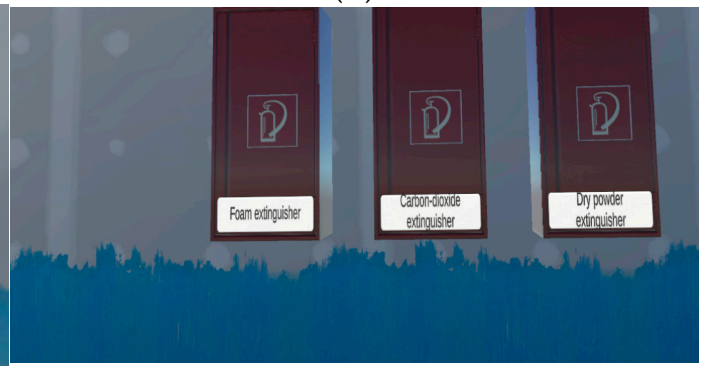

(f)

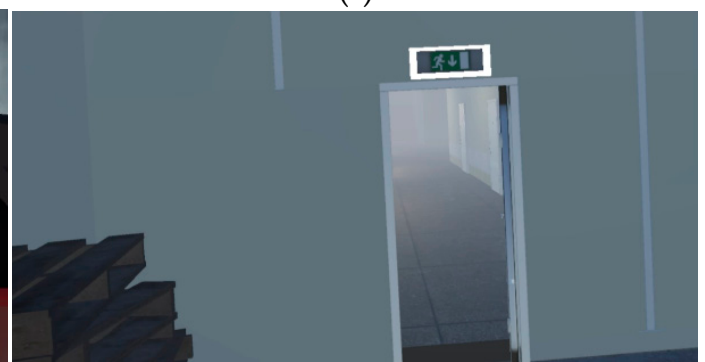

(h)

Figure 3. Selected elements of the VR environment dedicated to training for extinguishing an existing fire: (a) view of the production area; (b) elements of the trainee's protective equipment; (c) machine failure and initial fire phase; (d) machine emergency shutdown; (e) manual fire alarm activation; (f) fire extinguisher selection; (g) extinguishing a machine fire; (h) elements of evacuation signage.

Table 3. A summary of the similarities of the two target environments.

\begin{tabular}{|c|c|c|}
\hline Feature & The Academic Community & Industry 4.0 Environment \\
\hline Adapting to market needs & $\begin{array}{c}\text { Adapting educational programs and } \\
\text { teaching tools }\end{array}$ & $\begin{array}{l}\text { Adapting to quality and quantity needs } \\
\text { from customers and business partners }\end{array}$ \\
\hline Personal exchange & New student class & High mobility and movement of workers \\
\hline Technological volatility & $\begin{array}{l}\text { The need to implement the latest } \\
\text { technologies in the education process }\end{array}$ & $\begin{array}{l}\text { The need to implement the latest } \\
\text { technologies to make the Industry } 4.0 \\
\text { concept a reality }\end{array}$ \\
\hline Age diversity & $\begin{array}{l}\text { Students ranging from full-time part-time, } \\
\text { postgraduate and specialized courses and } \\
\text { training and third age students }\end{array}$ & Full range of employee ages \\
\hline Technological complexity & Exploring complex technological processes & $\begin{array}{l}\text { Need to understand and implement } \\
\text { complex technology processes }\end{array}$ \\
\hline
\end{tabular}

During the experiments, all participants were standing. It was possible to move participants through the so-called teleportation. The training was divided into four stages, each related to selected aspects of safety and user behavior in case of their occurrence (Figure 2). As part of VR technology initiation, stage zero (participant preparation) was available for users. This was training during which the user learned the principles of 
movement in the controller's VR and operation. To verify the effectiveness of the training, it was used to measure each of the four main stages by its participants. In this way, it was possible to verify how users cope with the execution of individual exercises and the entire scenario. Participants had the basic knowledge of VR, but until the training, did not use it actively. Each of the participants had to perform the entire exercise in one round, without changing the stages during the training and without prompting by the instructor. Their knowledge of the operation and implementation of individual actions were based on prompts implemented in the application, messages over the left hand/controller and information board.

Each user had four possible approaches in the same scenario. The goal of this task was to analyze how much time the user needed with each approach to be able to complete the entire scenario. The first approach was the most difficult because of the lack of knowledge of the scenario and sometimes the first contact with VR, which caused possible mistakes in operating the controller and moving in a virtual world. The last approach verified the acquired knowledge and also the trainee was able to operate the controllers fluently. Table 4 shows the results of the first five trainees by stage and approach. All given times are expressed in seconds.

Table 4. The results of the times achieved in each stage and approach for the first five VR training participants.

\begin{tabular}{|c|c|c|c|c|c|c|}
\hline User Number & Approach & Time of Stage I & Time of Stage II & Time of Stage III & Time of Stage IV & $\begin{array}{c}\text { Time of Complete } \\
\text { Scenario }\end{array}$ \\
\hline \multirow{4}{*}{ User 1} & Approach 1 & $00: 19,4$ & $00: 18,0$ & $01: 29,7$ & $00: 16,3$ & $02: 23,4$ \\
\hline & Approach 2 & $00: 15,1$ & $00: 16,5$ & $01: 18,2$ & $00: 14,2$ & $02: 04,0$ \\
\hline & Approach 3 & $00: 14,8$ & $00: 16,1$ & $01: 09,1$ & $00: 13,9$ & $01: 53,9$ \\
\hline & Approach 4 & $00: 13,2$ & $00: 16,2$ & $01: 05,3$ & $00: 12,7$ & $01: 47,4$ \\
\hline \multirow{4}{*}{ User 2} & Approach 1 & $00: 18,0$ & $00: 19,4$ & $01: 31,5$ & $00: 18,7$ & $02: 27,6$ \\
\hline & Approach 2 & $00: 15,1$ & $00: 17,4$ & $01: 24,5$ & $00: 16,7$ & $02: 13,7$ \\
\hline & Approach 3 & $00: 14,8$ & $00: 15,4$ & $01: 21,9$ & $00: 15,1$ & $02: 07,2$ \\
\hline & Approach 4 & $00: 13,2$ & $00: 14,6$ & $01: 16,4$ & $00: 13,4$ & $01: 57,6$ \\
\hline \multirow{4}{*}{ User 3} & Approach 1 & $00: 21,5$ & $00: 21,4$ & $01: 26,4$ & $00: 17,3$ & $02: 26,6$ \\
\hline & Approach 2 & $00: 17,8$ & $00: 18,6$ & $01: 20,1$ & $00: 15,4$ & $02: 11,9$ \\
\hline & Approach 3 & $00: 16,7$ & $00: 17,4$ & $01: 11,8$ & $00: 14,9$ & $02: 00,8$ \\
\hline & Approach 4 & $00: 13,2$ & $00: 15,9$ & $01: 08,6$ & $00: 12,8$ & $01: 50,5$ \\
\hline \multirow{4}{*}{ User 4} & Approach 1 & $00: 23,4$ & $00: 19,4$ & $01: 28,4$ & $00: 19,1$ & $02: 30,3$ \\
\hline & Approach 2 & $00: 18,4$ & $00: 18,6$ & $01: 21,6$ & $00: 17,3$ & $02: 15,9$ \\
\hline & Approach 3 & $00: 15,6$ & $00: 16,7$ & $01: 14,9$ & $00: 16,2$ & $02: 03,4$ \\
\hline & Approach 4 & $00: 14,7$ & $00: 13,9$ & $01: 09,8$ & $00: 14,9$ & $01: 53,3$ \\
\hline \multirow{4}{*}{ User 5} & Approach 1 & $00: 19,8$ & $00: 19,6$ & $01: 24,3$ & $00: 17,6$ & $02: 21,3$ \\
\hline & Approach 2 & $00: 17,5$ & $00: 17,4$ & $01: 18,6$ & $00: 16,7$ & $02: 10,2$ \\
\hline & Approach 3 & $00: 14,3$ & $00: 15,9$ & $01: 12,4$ & $00: 15,1$ & $01: 57,7$ \\
\hline & Approach 4 & $00: 12,9$ & $00: 15,2$ & $01: 07,7$ & $00: 13,8$ & $01: 49,6$ \\
\hline
\end{tabular}

As can be seen in Figure 4, the time in each approach differs from the one before. The scenario's mentioned knowledge influences the next approach's given result and better familiarity with the VR controllers. The training showed that the participants performed much better in the subsequent approaches. Thanks to practical training, they had the possibility to extend their knowledge and acquire new skills in a more effective way than in the case of purely theoretical classes.

Figure 5 shows the effects of training in the time domain for each participant's approach to realize tasks prepared for them in the first stage (stage I). For the individual graphs, it was assumed that the vertical axis represents the individual participants and the horizontal axis indicates the time to perform a given stage in each of the four approaches. As can be seen, there is a significant difference in time between completing the task in the first, second and third approaches. This is due to the knowledge of what awaits the user in 
a given stage. In the second attempt, it can be seen that the participant knew what to expect and gained knowledge about the actions to perform to move on and the efficiency in their implementation. Differences between the second and third attempts are also noticeable, as is the time difference between the first and second attempts. In the third approach, the user becomes more skilled and familiar with the VR around him.

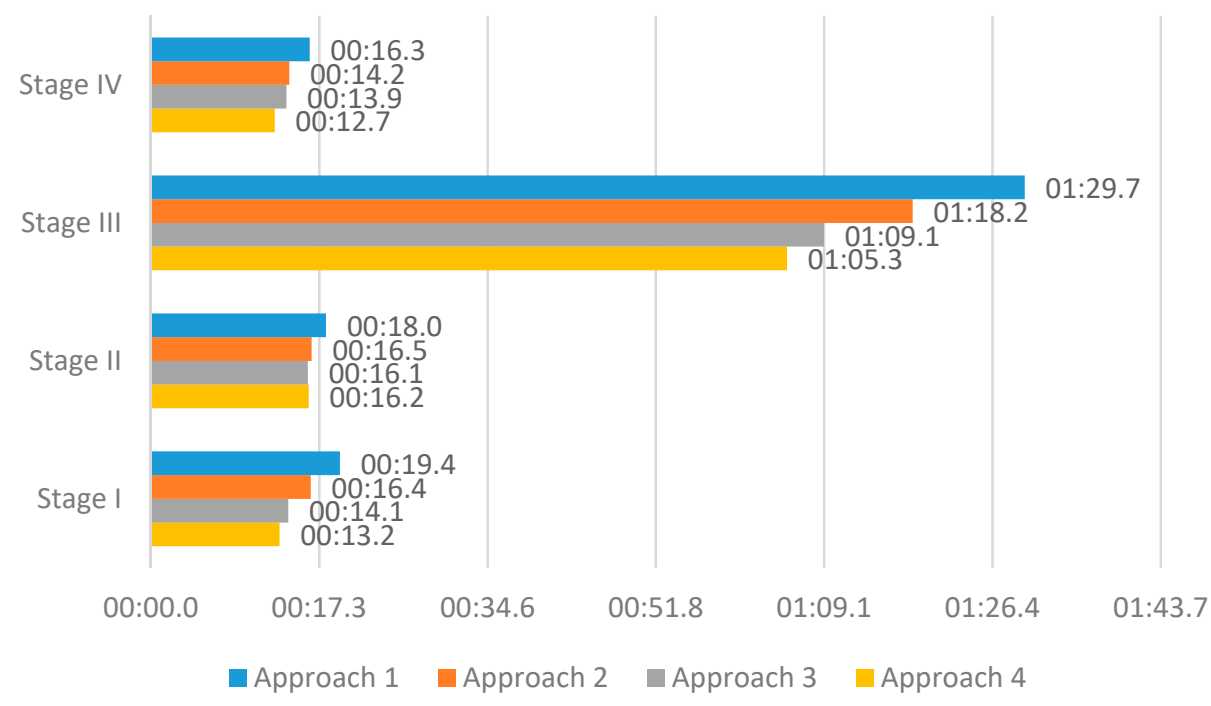

Figure 4. The individual approach scores of the first participant in the set stages.

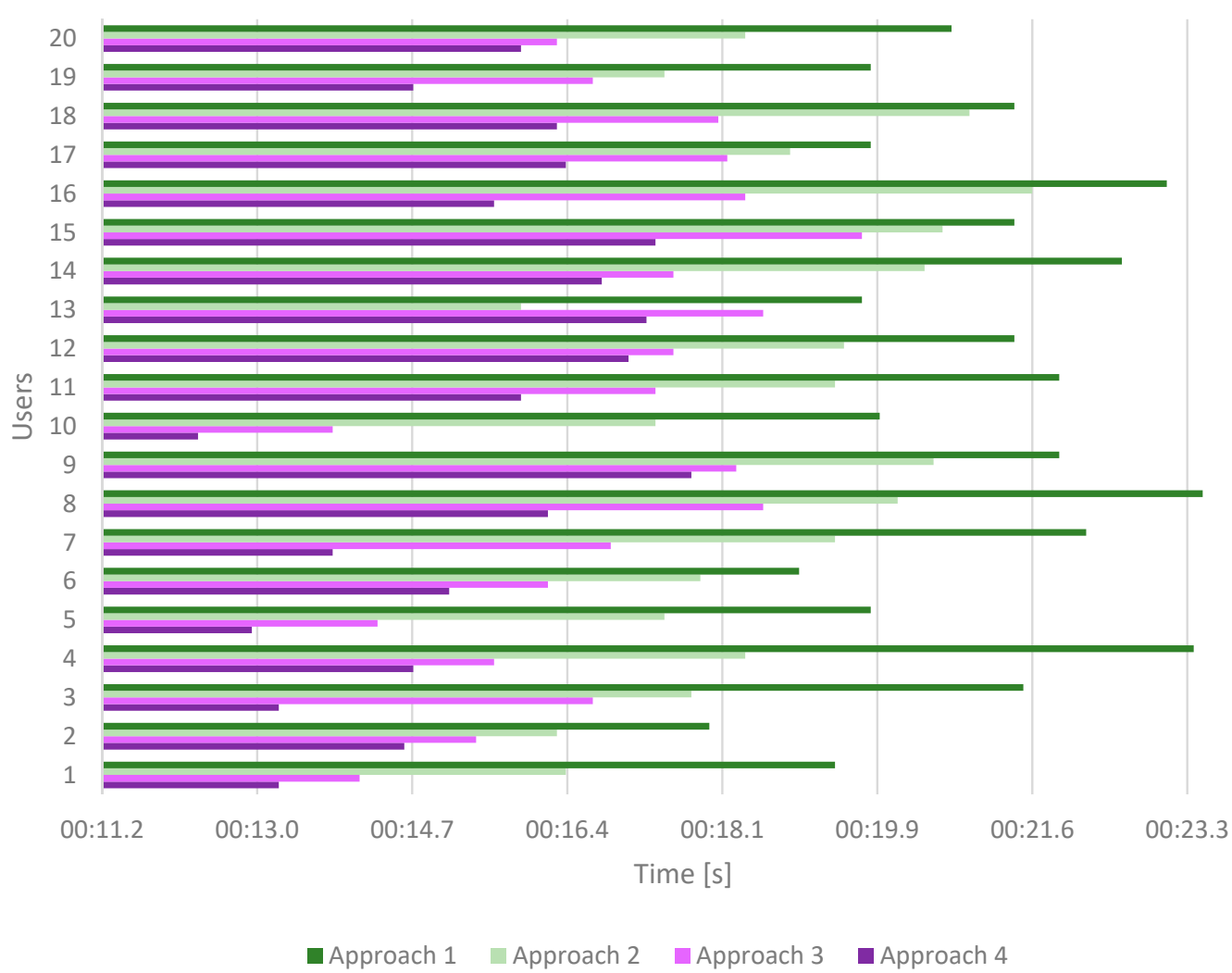

Figure 5. Presentation of all participants' performance by approaches to task completion in stage one.

In most cases, the differences between the third and fourth attempts are not so significant. In the case of the fourth approach, the user is more focused on improving his time as he already knows the scheme. To analyze the exercise execution time, it was assumed that each trainee would perform four trials. 
The second stage (stage II) focused on reaching and activating a manual call point. The longest time to complete the task in this stage in the first approach was $22 \mathrm{~s}$. As shown in Figure 6, the difference between approaches two, three and four for all participants is no longer as significant as for stage one. However, one can see a significant difference between the first and second approaches. As in the case of stage one, this is due to the gradual learning of the exercise in question and the permanent improvement of the ability to function in the VR environment. It was noticeable that during the first approach, the participant was more focused on the prompts received during the implementation of individual activities. However, during subsequent attempts, such situations were becoming less frequent.

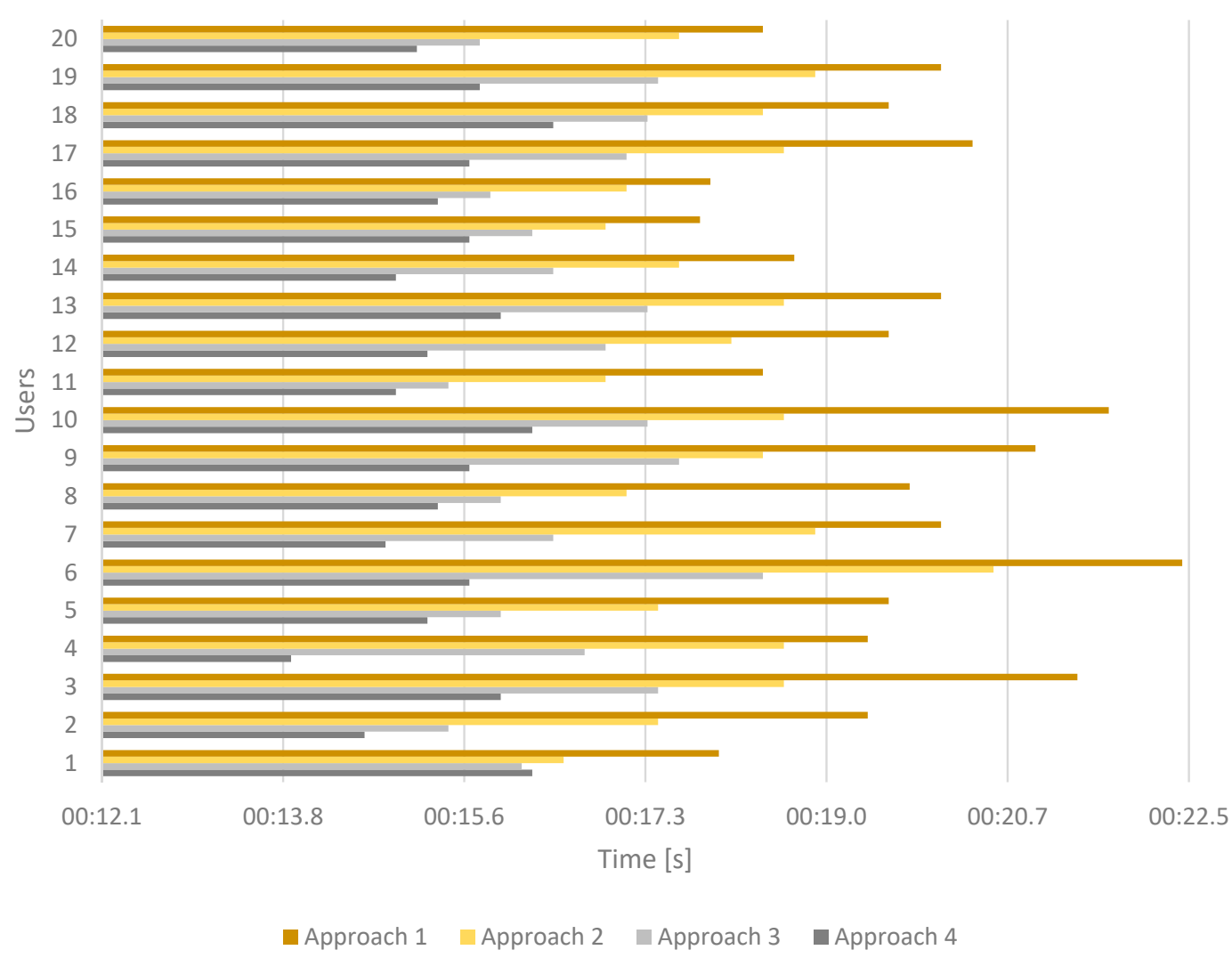

Figure 6. Presentation of all participants' performance by approaches to task completion in stage two.

The third stage (stage III), because of the defined tasks, is the most complicated and time-consuming. During its implementation, the user must perform a much larger number of activities to be able to complete the exercise. The participant has to select the appropriate fire extinguisher from three available, unlock it, approach the CNC machine and extinguish the fire. Depending on the user's knowledge about choosing the suitable fire extinguisher and the ability to extinguish the fire, the time of completing the exercise varied. Detailed results are presented in Figure 7.

In the case of the third stage, there are apparent time differences between the different approaches. The first approach, where the user gets familiar with the stage's rules and tries to extinguish the fire in different ways, usually takes a relatively long time. However, this stage shows that the knowledge of what is going to happen is not the primary determinant of the possibility of reducing the time of task completion. Among the participants, it was clear that the biggest challenge was to find an effective way to extinguish the virtual flames. Each person taking part in the exercise had a different extinguishing technique and it was clearly visible to test different ways in subsequent approaches. This stage proves that in the case of stressful situations, even taking place in a virtual environment, it is impossible to determine the time of execution of a given task unambiguously. General manual skills 
of individual participants have a significant influence on the efficiency of the exercise. The participants had to reach the assembly point in the final stage (stage IV) by following the rooms' signs. This task was relatively short compared to the others, but it aimed to develop proper behavior among trainees. The results of this stage are shown in Figure 8.

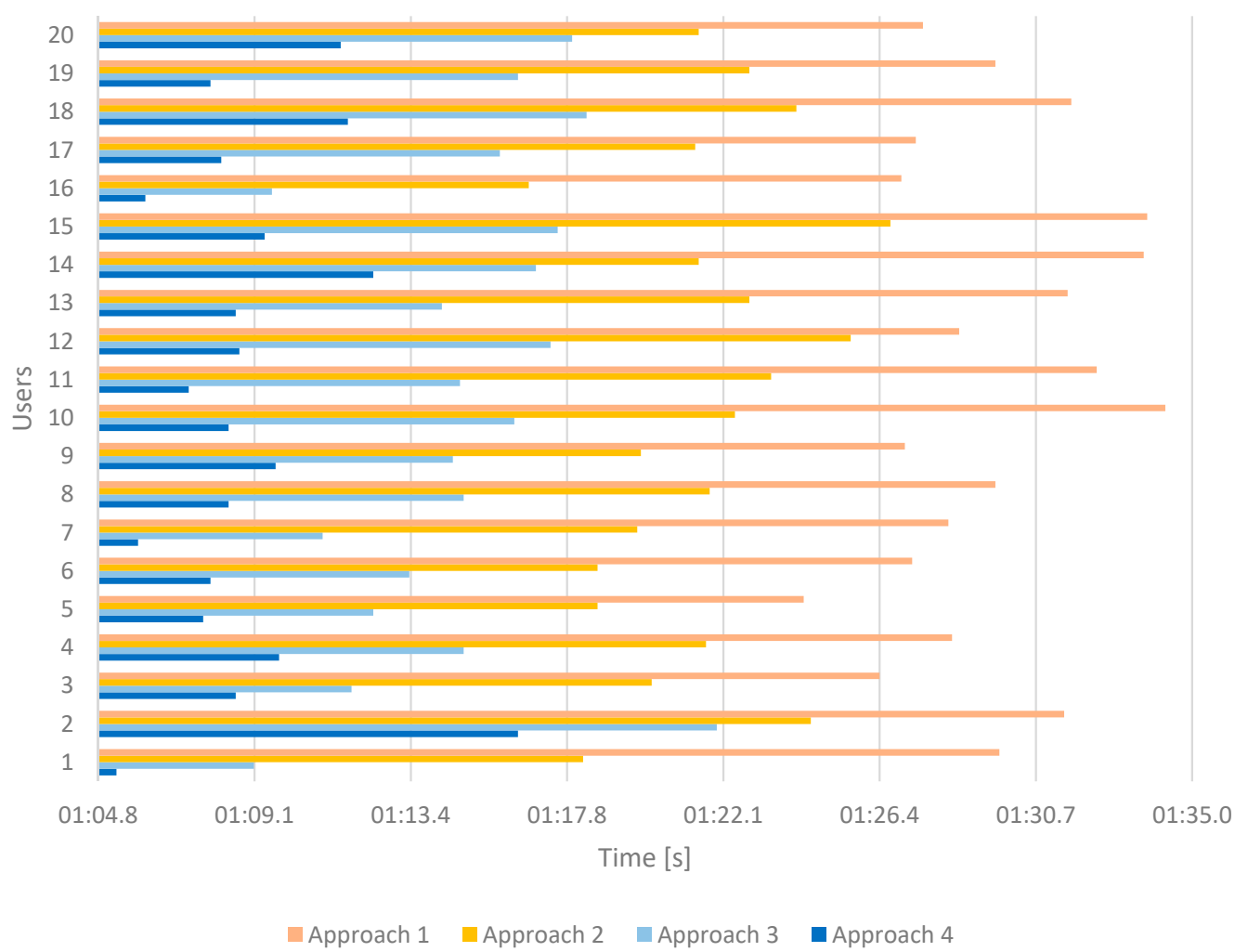

Figure 7. Presentation of all participants' performance by approaches to task completion in stage three.

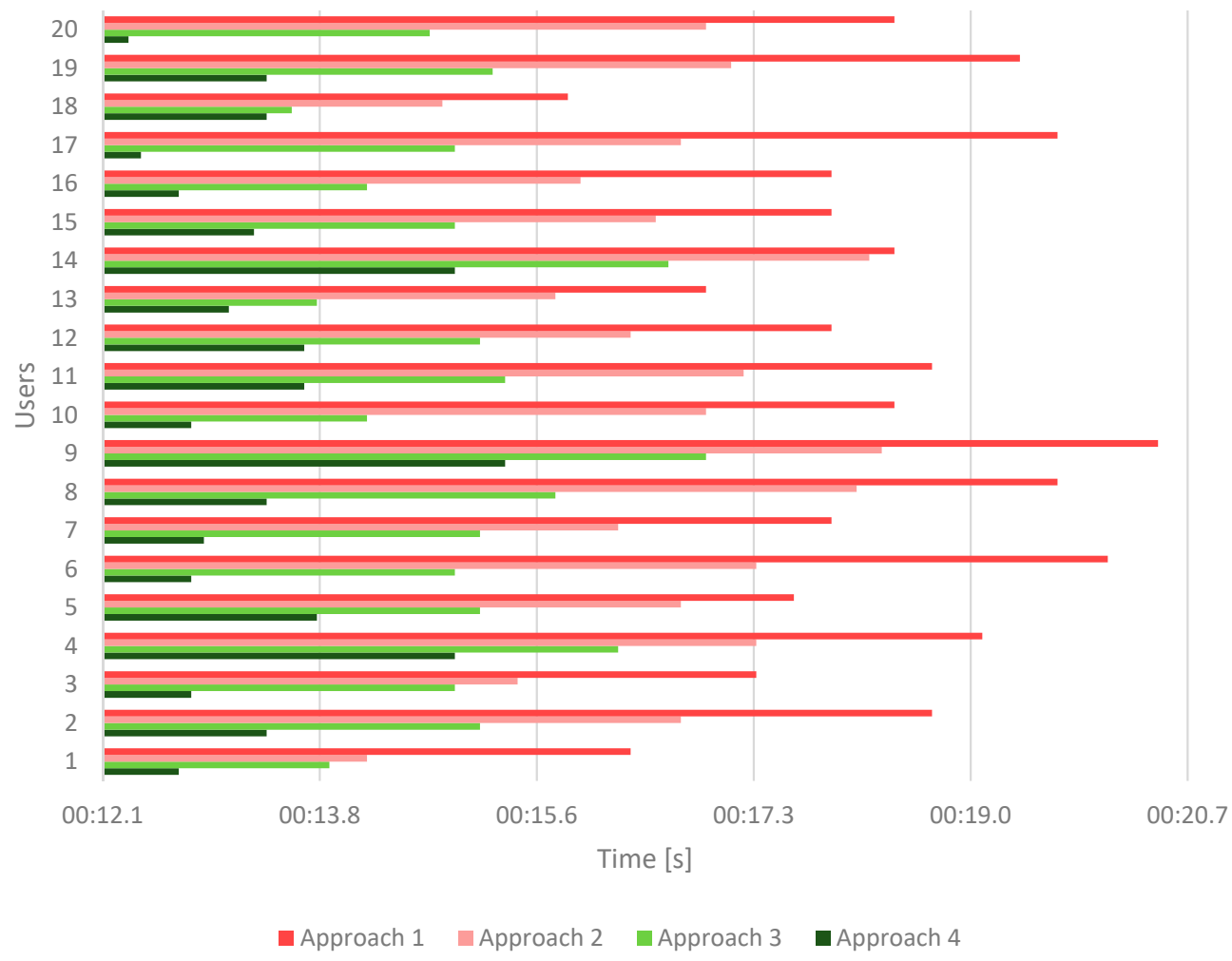

Figure 8. Presentation of all participants' performance by approaches to task completion in stage four. 
As in the previous stages, a similar situation occurs. The first approach differs significantly in time from the second, third or fourth approach. Here, as in stages one and two, the key element is orientation and reaction time to events. The main determinant of time was the reaction to the extinguished fire. This was the factor that most often influenced the time obtained, especially in the final approaches, where the participant already knew the final solution.

Figure 9 presents each participant's total time to complete the entire training scenario, four stages in total. Sequential execution of all four stages was necessary to complete the fire safety training. It can be seen on the graph that each user consistently improved his performance with each successive attempt. Significant differences in the achieved times were seen in each of the four stages. However, the most significant impact on the whole task was seen in stage III-selecting the extinguisher and fire extinguishing. The results presented in Figure 7 showed that this was the longest part of the whole training scenario.

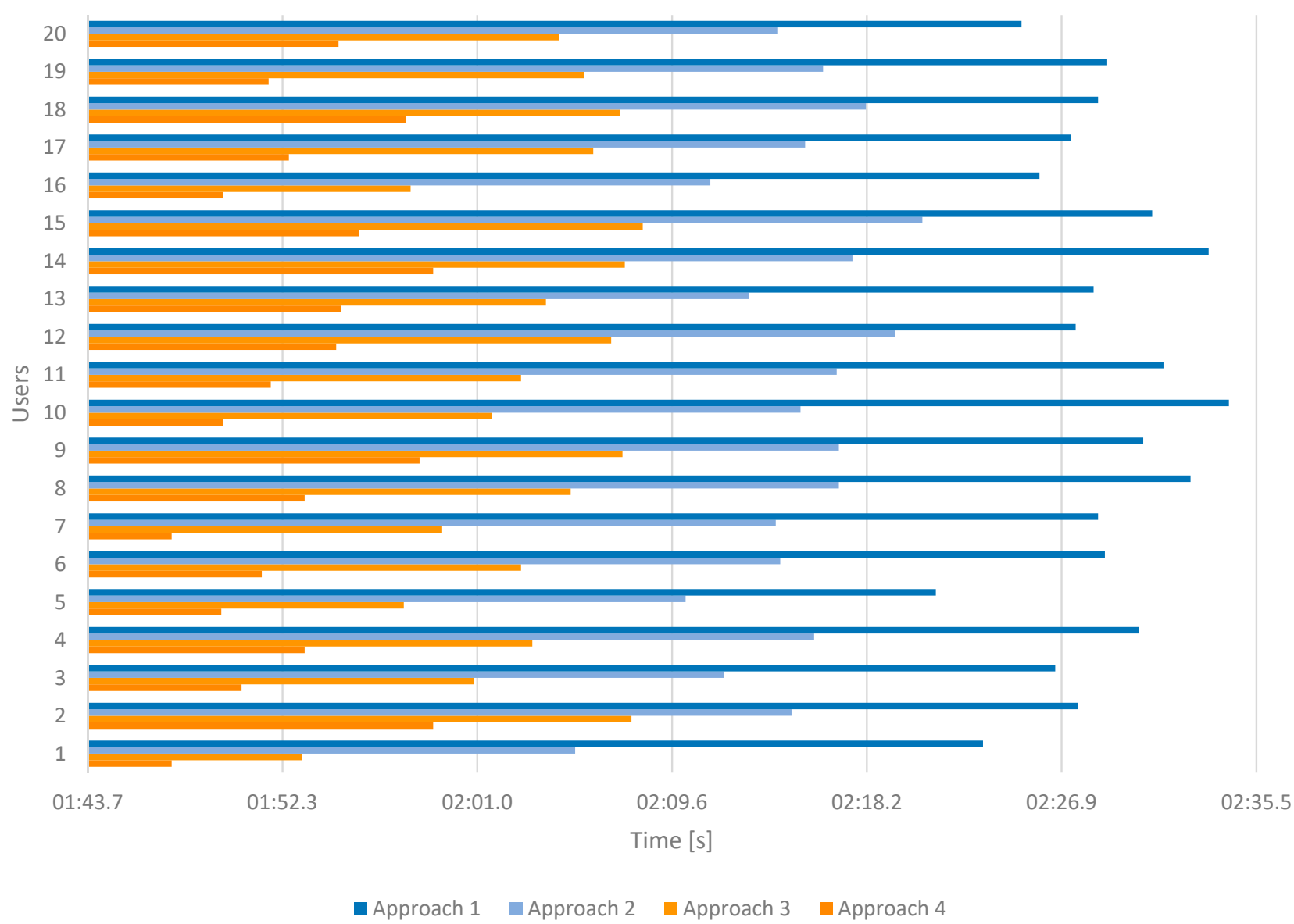

Figure 9. Presentation of all participants' performance by approaches of the whole OHS scenario completion.

Two main limitations of the proposed methodology were identified during the study. A critical stage from the point of view of methodology is the implementation phase and in particular, the programming stage. Proper implementation of this stage requires hiring specialized programmers who can create VR environment. Currently, there is a noticeable lack of such specialists on the market and the costs associated with their employment are very high. This may have a negative impact on both the time and the cost increase of project implementation.

On the other hand, the proposed methodology precisely defines at the earlier stages the exact scope of work and the guidelines for their implementation, thanks to which the team of programmers receives a strictly defined scenario for implementation along with all the necessary graphic elements. This allows to reduce the time needed for scenario 
programming and, thus, keep the costs to a minimum and the model of outsourcing of services. Among lower and middle-level technical staff, a small group of digitally excluded people have never used, or have used little, ICT tools. Their use of VR systems can be associated with high stress, which makes the process of effective training difficult and in some cases impossible. Government programs fighting digital exclusion and the growing number of employees for whom information systems are a natural working tool limit this phenomenon's negative impact on the implementation of the proposed methodology.

An example implementation of the presented methodology in the process of creating a virtual training in the performance of the procedure for extinguishing a fire in a given object, i.e., at the machine workstation in the factory, confirmed its capabilities. In addition, during the training, the first approaches of participants are aimed at familiarizing themselves with the new environment. Thus, with subsequent approaches, it increased the level of freedom to move in the virtual world and the quality and pace of execution of activities related to the planned training scenario. Assuming multiple repetitions of the exact or modified training instructions, it is possible, without additional costs, to improve employees' qualifications, especially those dedicated to specialized positions in the industry. An essential aspect is also the limitation of dangerous situations. Especially workers with little experience could be exposed and the limitation of possible costs of destruction and damage to real components, materials and equipment.

What is more, referring to the presented exemplary training, it can be assumed that the participant will behave much better in life-threatening situations than if the training was only theoretical. Considering the mentioned advantages, it can be concluded that the use of VR technology in the process of training staff for Industry 4.0 reduces costs and shortens the time needed for their implementation in the production environment. Thus, it shows great potential for application in epidemics, natural disasters, or limitations resulting from residence.

Due to the epidemiological constraints associated with COVID-19 the study had to be conducted under a strict sanitary regime. Therefore, at the stage of designing the study authors decided to make a preliminary selection of participants. The limited number of them would be representative for both engineers from industry and students studying engineering. Obviously, in the following stages of the research, it is planned to develop other scenarios using the proposed methodology and conduct research on a much wider group of people. However, it should be kept in mind that test groups' size would strongly depend on the actual epidemic boundaries.

\section{Conclusions}

The development of VR technologies and the availability of tools dedicated to these technologies allow for their use in many areas of social, economic and educational life. They are already widely known applications in the entertainment industry, such as games. However, along with the growing awareness of the potential of VR, there are attempts to create dedicated, specialized virtual environments focused on the specific needs of individual industries. Consequently, the need arises to develop, on the one hand, a universal but also comprehensive methodology to facilitate the design and creation of VR-based training. Therefore, this paper presents a new approach considering the different phases and stages of creating such courses and their implementation in an actual learning process aimed mainly at the needs of realizing the Industry 4.0 concept. This methodology takes into account the necessary elements and activities related to the development of training. Moreover, it allows for their appropriate evaluation and possible improvement. The approach taken into account here refers to a spiral model, making it possible to improve the quality of the solutions created consistently. The research resulted in a unified and comprehensive approach to designing, implementing and developing training focused on the needs of Industry 4.0 based on the VR environment. Thus, the goal of the project to develop a solution for systematizing, planning and realization of the design and development work in the area of projects based on VR technology for the needs of Industry 4.0 
has been achieved. The use of the presented methodology can strengthen the confidence of team members in the management, coordination and execution of individual phases and stages, as well as the entire project. This provided a solution to facilitate the planning and implementation of projects in the areas mentioned above. Therefore, the use of this methodology can contribute to a better organization of several works whose final goal is to create effective training. It is also essential to clearly define the moments of involvement and cooperation of particular teams of specialists. In this way, it is also possible to involve interdisciplinary teams from different entities. In order to confirm the effectiveness of the proposed methodology, a sample new VR course was created using this methodology and its effectiveness in the area of engineers training was confirmed.

What is more, this approach provides a possibility of internal realization of planned work and outsourcing of selected stages. In addition to the above features of novelty, the proposed methodology can also be seen in terms of a reference model or even a form of standardization of the design and manufacturing process. All these features can positively influence the quality of the course and shorten the time of its development. At the same time, it should be noted that the limitations presented by the authors in Section 4 related to the deficit of specific specialists on the market and the lack of user experience in the VR environment do not significantly affect the level and scope of its use.

Based on the obtained methodology, further research has been initiated. In the short and long term, this research would include such issues as the development of dedicated VR environments focused on the needs of Industry 4.0, or the development and verification of performance indicators taking into account the individual nature of specific training carried out using VR. An example of such research is developing a VR environment dedicated to the needs of industry in the operation of numerically controlled machines and remote control of single and multi-machine robots and control of rapid prototyping process using VR technology. Moreover, using the knowledge and experience gained during the research, it is planned to start work on the development of assumptions and recommendations for creating the VR environment and then its implementation in the university education system in the field of computer science and automation robotics.

Author Contributions: Researched the literature, A.P., M.S., P.D., M.B., G.B.; developing a methodology, A.P.; software, A.P., M.S., P.K.; assumptions of the experiment, A.P., M.S., P.D., M.B., G.B., P.K.; conducting experiments A.P., M.S., P.D., M.B., G.B.; data collection and analysis, A.P., M.S., P.D., M.B., G.B., P.K.; supervision, A.P. to contributed to writing of this paper, A.P., M.S., P.D., M.B., G.B., P.K. All authors have read and agreed to the published version of the manuscript.

Funding: This project is financed by the Minister of Education and Science of the Republic of Poland within the "Regional Initiative of Excellence" program for years 2019-2022. Project number 027/RID/2018/19, amount granted 11999900 PLN.

Institutional Review Board Statement: Not applicable.

Informed Consent Statement: Not applicable.

Data Availability Statement: Data available on request due to restrictions.

Conflicts of Interest: The authors declare no conflict of interest.

\section{References}

1. Maresova, P.; Soukal, I.; Svobodova, L.; Hedvicakova, M.; Javanmardi, E.; Selamat, A.; Krejcar, O. Consequences of Industry 4.0 in Business and Economics. Economies 2018, 6, 46. [CrossRef]

2. Pereira, A.C.; Romero, F. A review of the meanings and the implications of the Industry 4.0 concept. Procedia Manuf. 2017, 13, 1206-1214. [CrossRef]

3. Paszkiewicz, A.; Bolanowski, M.; Budzik, G.; Przeszłowski, Ł.; Oleksy, M. Process of Creating an Integrated Design and Manufacturing Environment as Part of the Structure of Industry 4.0. Processes 2020, 8, 1019. [CrossRef]

4. Wollschlaeger, M.; Sauter, T.; Jasperneite, J. The Future of Industrial Communication: Automation Networks in the Era of the Internet of Things and Industry 4.0. IEEE Ind. Electron. Mag. 2017, 11, 17-27. [CrossRef]

5. Chen, Y.; Han, Z.; Cao, K.; Zhang, X.; Xu, X. Manufacturing upgrading in industry 4.0 era. Syst. Res. Behav. Sci. 2020, 37, 766-771. [CrossRef] 
6. $\quad$ Lin, K.C.; Shyu, J.Z.; Ding, K. A Cross-Strait Comparison of Innovation Policy under Industry 4.0 and Sustainability Development Transition. Sustainability 2017, 9, 786. [CrossRef]

7. Liao, Y.; Deschamps, F.; de Freitas Rocha Loures, E.; Felipe Pierin Ramos, L. Past, present and future of Industry 4.0-A systematic literature review and research agenda proposal. Int. J. Prod. Res. 2017, 55, 3609-3629. [CrossRef]

8. Cruz-Neira, C.; Fernández, M.; Portalés, C. Virtual Reality and Games. Multimodal Technol. Interact. 2018, 2, 8. [CrossRef]

9. Abich, J.; Parker, J.; Murphy, J.S.; Eudy, M. A review of the evidence for training effectiveness with virtual reality technology. Virtual Real. 2021, 1-15. Available online: https:/ / doi.org/10.1007/s10055-020-00498-8 (accessed on 29 April 2021).

10. Kavanagh, S.; Luxton-Reilly, A.; Wuensche, B.; Plimmer, B. A systematic review of Virtual Reality in education. Themes Sci. Technol. Educ. 2017, 10, 85-119.

11. Kovar, J.; Mouralova, K.; Ksica, F.; Kroupa, J.; Andrs, O.; Hadas, Z. Virtual reality in context of Industry 4.0 proposed projects at Brno University of Technology. In Proceedings of the 17th International Conference on Mechatronics-Mechatronika (ME), Prague, Czech Republic, 7-9 December 2016.

12. Roldán, J.J.; Crespo, E.; Martín-Barrio, A.; Peña-Tapia, E.; Barrientos, A. A training system for Industry 4.0 operators in complex assemblies based on virtual reality and process mining. Robot. Comput. Integr. Manuf. 2019, 59, 305-316. [CrossRef]

13. Kuts, V.; Otto, T.; Caldarola, E.G.; Modoni, G.E.; Sacco, M. Enabling the teaching factory leveraging a virtual reality system based on the digital twin. In Proceedings of the 15th Annual EuroVR Conference, London, UK, 22-23 October 2018; VTT Technical Research Centre of Finland, Ltd.: Espoo, Finland, 2018; pp. 26-31.

14. Singh, R.P.; Javaid, M.; Kataria, R.; Tyagi, M.; Haleem, A.; Suman, R. Significant applications of virtual reality for COVID-19 pandemic. Diabetes Metab. Syndr. 2020, 14, 661-664. [CrossRef]

15. Tabatabai, S. COVID-19 impact and virtual medical education. J. Adv. Med. Educ. Prof. 2020, 8, 140-143. [PubMed]

16. Li, X.; Yi, W.; Chi, H.; Wang, X.; Chan, A.P. A critical review of virtual and augmented reality (VR/AR) applications in construction safety. Autom. Constr. 2018, 86, 150-162. [CrossRef]

17. Zhao, D.; Lucas, J. Virtual reality simulation for construction safety promotion. Int. J. Inj. Control. Saf. Promot. 2015, 22, 57-67. [CrossRef] [PubMed]

18. Heilig, M. Sensorama Simulator. U.S. Patent 3,050,870, 1962. Available online: https://patents.google.com/patent/US3050870A/ en (accessed on 29 April 2021).

19. Fedorov, N. The History of Virtual Reality. Available online: https:/ /www.avadirect.com/blog/the-history-of-virtual-reality/ (accessed on 19 March 2021).

20. Heilig, M. Stereoscopic-Television Apparatus for Invidual Use. U.S. Patent 2,955,156, 1960. Available online: https://patents. google.com/patent/US2955156A/en (accessed on 29 April 2021).

21. Sutherland, I.E. The Ultimate Display. In Proceedings of the IFIP Congress; Macmillan and Co.: London, UK, 1956; pp. 506-508.

22. Sutherland, I.E. A Head-Mounted Three-Dimensional Display. In Proceedings of the AFIPS Conference, San Francisco, CA, USA, 9-11 December 1968; pp. 757-764.

23. Delprat, N.; Leroux, C.; Alaoui, S.F. Experience of a cloud-avatar: Scientific challenges and artistic perspectives. Int. J. Des. Innov. Res. 2011, 6, 127-143.

24. Zimmerman, T.G. An Optical Flex Sensor. U.S. Patent 4542291, 1982. Available online: https://patents.google.com/patent/US4 542291A/en (accessed on 29 April 2021).

25. Kocian, D.F. A visually-coupled airborne systems simulator (VCASS)—An approach to visual simulation. In Proceedings of the IMAGE Conference Sponsored by Air Force Human Resources Laboratory, Williams Air Force Base, AZ, USA, 17-18 May 1977.

26. Cruz-Neira, C.; Sandin, D.; Defant, T.A.; Kenyon, R.C.; Hart, J.C. The cave-audio visual experience virtual environment. Commun. ACM 1992, 35, 65-72. [CrossRef]

27. Li, Y.; Zhang, J.; Sun, W.; Wang, J.; Gao, X. VREX: Virtual reality education expansion could help to improve the class experience (VREX platform and community for VR based education). In Proceedings of the IEEE Frontiers in Education Conference (FIE), Indianapolis, IN, USA, 18-21 October 2017; pp. 1-5.

28. Seo, J.H.; Smith, B.M.; Cook, M.; Malone, E.; Pine, M.; Leal, S.; Bai, Z.; Suh, J. Anatomy builder VR: Applying a constructive learning method in the virtual reality canine skeletal system. In Proceedings of the International Conference on Applied Human Factors and Ergonomics, Los Angeles, CA, USA, 17-21 July 2017; pp. 245-252.

29. Marsh, A.; Simistira, F.; Robb, R. VR in medicine: Virtual colonoscopy. Future Gener. Comput. Syst. 1998, 14, 253-264. [CrossRef]

30. Pensieri, C.; Pennacchini, M. Overview: Virtual Reality in Medicine. J. Virtual Worlds Res. 2014, 7, 1-33. [CrossRef]

31. Borst, C.W.; Ritter, K.A.; Chambers, T.L. Virtual energy center for teaching alternative energy technologies. In Proceedings of the IEEE Virtual Reality (VR), Greenville, SC, USA, 19-23 March 2016; pp. 157-158.

32. Bell, J.T.; Fogler, H.S. Virtual Reality in The Chemical Engineering Classroom. In Proceedings of the American Society for Engineering Education Annual Conference, Seattle, WA, USA, 28 June-1 July 1998.

33. Peña, A.M.; Ragan, E.D. Contextualizing construction accident reports in virtual environments for safety education. In Proceedings of the IEEE Virtual Reality (VR), Los Angeles, CA, USA, 18-22 March 2017; pp. 389-390.

34. Mazuryk, T.; Gervautz, M. Virtual Reality-History, Applications, Technology and Future; Vienna University of Technology: Vienna, Austria, 1996. 
35. Raikwar, A.; D'Souza, N.; Rogers, C.; Kress, M.; Williams, A.; Rishe, N.D.; Ortega, F.R. CubeVR: Digital Affordances for Architecture Undergraduate Education using Virtual Reality. In Proceedings of the IEEE Conference on Virtual Reality and 3D User Interfaces (VR), Osaka, Japan, 23-27 March 2019; pp. 1623-1626.

36. Nickel, P.; Pröger, E.; Lungfiel, A.; Kegel, R. Flexible, dynamic VR simulation of a future river lock facilitates prevention through design in occupational safety and health. In Proceedings of the 2015 IEEE Virtual Reality (VR), Arles, France, 23-27 March 2015; pp. 385-386.

37. Raposo, A.; Santos, I.; Soares, L.; Wagner, G.; Corseuil, E.; Gattass, M. Environ: Integrating VR and CAD in Engineering Projects. IEEE Comput. Graph. Appl. 2009, 29, 91-95. [CrossRef]

38. Kim, D.; Yoon, Y.; Hwang, S.; Lee, G.; Park, J. Visualizing Spray Paint Deposition in VR Training. In Proceedings of the IEEE Virtual Reality Conference, Charlotte, NC, USA, 10-14 March 2007; pp. 307-308.

39. Nguyen, L.; Bualat, M.; Edwards, L.; Flueckiger, L.; Neveu, C.; Schwehr, K.; Wagner, M.D.; Zbinden, E. Virtual reality interfaces for visualization and control of remote vehicles. Auton. Robot. 2001, 11, 59-68. [CrossRef]

40. Lozé, S. Beyond the Manual: VR Training on Aircraft Maintenance. Available online: https://www.unrealengine.com/en-US/ spotlights/beyond-the-manual-vr-training-on-aircraft-maintenance (accessed on 19 March 2021).

41. The Virtual Maintenance Trainer. Available online: https://www.13harris.com/all-capabilities/virtual-maintenance-trainer (accessed on 19 March 2021).

42. Garcia, C.A.; Naranjo, J.E.; Ortiz, A.; Garcia, M.V. An Approach of Virtual Reality Environment for Technicians Training in Upstream Sector. IFAC-Paperonline. 2019, 52, 285-291. [CrossRef]

43. Burghardt, A.; Szybicki, D.; Gierlak, P.; Kurc, K.; Pietruś, P.; Cygan, R. Programming of Industrial Robots Using Virtual Reality and Digital Twins. Appl. Sci. 2020, 10, 486. [CrossRef]

44. Ruppert, T.; Jaskó, S.; Holczinger, T.; Abonyi, J. Enabling Technologies for Operator 4.0: A Survey. Appl. Sci. 2018, 8, 1650. [CrossRef]

45. Häfner, P.; Häfner, V.; Ovtcharova, J. Teaching Methodology for Virtual Reality Practical Course in Engineering Education. Procedia Comput. Sci. 2013, 25, 251-260. [CrossRef]

46. Sanchez-Sepulveda, M.V.; Torres-Kompen, R.; Fonseca, D.; Franquesa-Sanchez, J. Methodologies of Learning Served by Virtual Reality: A Case Study in Urban Interventions. Appl. Sci. 2019, 9, 5161. [CrossRef]

47. Hamilton, D.; McKechnie, J.; Edgerton, E.; Wilson, C. Immersive virtual reality as a pedagogical tool in education: A systematic literature review of quantitative learning outcomes and experimental design. J. Comput. Educ. 2021, 8, 1-32. [CrossRef]

48. Azevich, A.I. Virtual reality: Educational and methodological aspects. Rudn J. Informatiz. Educ. 2019, 16, 338-350. [CrossRef]

49. Salah, B.; Abidi, M.H.; Mian, S.H.; Krid, M.; Alkhalefah, H.; Abdo, A. Virtual Reality-Based Engineering Education to Enhance Manufacturing Sustainability in Industry 4.0. Sustainability 2019, 11, 1477. [CrossRef]

50. Mourtzis, D.; Vlachou, E.; Dimitrakopoulos, G.; Zogopoulos, V. Cyber- Physical Systems and Education 4.0 -The Teaching Factory 4.0 Concept. Procedia Manuf. 2018, 23, 129-134. [CrossRef]

51. Jimeno-Morenilla, A.; Sánchez-Romero, j.L.; Mora-Mora, H.; Coll-Miralles, R. Using virtual reality for industrial design learning: A methodological proposal. Behav. Inf. Technol. 2016, 35, 897-906. [CrossRef]

52. Velosa, J.D.; Cobo, L.; Castillo, F.; Castillo, C. Methodological Proposal for Use of Virtual Reality VR and Augmented Reality AR in the Formation of Professional Skills in Industrial Maintenance and Industrial Safety. In Online Engineering $\mathcal{E}$ Internet of Things. Lecture Notes in Networks and Systems; Auer, M., Zutin, D., Eds.; Springer: Cham, Switzerland, 2018; Volume 22, pp. 987-1000.

53. Cotet, G.B.; Carutasu, N.L.; Chiscop, F. Industry 4.0 Diagnosis from an iMillennial Educational Perspective. Educ. Sci. 2020, 10, 21. [CrossRef]

54. González, I.; Calderón, A.J. Development of Final Projects in Engineering Degrees around an Industry 4.0-Oriented Flexible Manufacturing System: Preliminary Outcomes and Some Initial Considerations. Educ. Sci. 2018, 8, 214. [CrossRef]

55. Mian, S.H.; Salah, B.; Ameen, W.; Moiduddin, K.; Alkhalefah, H. Adapting Universities for Sustainability Education in Industry 4.0: Channel of Challenges and Opportunities. Sustainability 2020, 12, 6100. [CrossRef]

56. Salah, B.; Khan, S.; Ramadan, M.; Gjeldum, N. Integrating the Concept of Industry 4.0 by Teaching Methodology in Industrial Engineering Curriculum. Processes 2020, 8, 1007. [CrossRef]

57. Ferrara, M.; Lucibello, S. Teaching material design. Research on teaching methodology about materials in industrial design. Strateg. Des. Res. J. 2012, 5, 75-78. [CrossRef]

58. Sampaio, A.Z. Introduction of BIM methodology in education: Concept and application. In Proceedings of the Fourth International Conference on Higher Education Advances, Valencia, Spain, 20-22 June 2018.

59. Weidig, C.H.; Menck, N.; Winkes, P.A.; Aurich, J.C. Virtual Learning Factory on VR-Supported Factory Planning. In Proceedings of the 15th IFIP WG 5.5 Working Conference on Virtual Enterprises, PRO-VE 2014, Amsterdam, The Netherlands, 6-8 October 2014; pp. 455-462. 